Research Article

\title{
Investigation of Stochastic Seismic Response and Index Correlation of an Arch Dam Using Endurance Time Analysis Method
}

\author{
Qiang Xu, ${ }^{1,2}$ Shutong $X u \mathbb{D}^{2},{ }^{2}$ Jianyun Chen, ${ }^{1,2}$ and Jing $\mathrm{Li}^{1,2}$ \\ ${ }^{1}$ State Key Laboratory of Coastal and Offshore Engineering, Dalian University of Technology, Dalian 116024, China \\ ${ }^{2}$ Faculty of Infrastructure Engineering, Dalian University of Technology, Dalian 116024, China \\ Correspondence should be addressed to Shutong Xu; xushutong@mail.dlut.edu.cn
}

Received 18 March 2020; Revised 23 July 2020; Accepted 18 August 2020; Published 29 August 2020

Academic Editor: Hayri Baytan Ozmen

Copyright (c) 2020 Qiang Xu et al. This is an open access article distributed under the Creative Commons Attribution License, which permits unrestricted use, distribution, and reproduction in any medium, provided the original work is properly cited.

\begin{abstract}
The seismic dynamic response and correlation between various indicators of an arch dam under a series of stochastic earthquake excitation are analysed. Seismic response assessment of a concrete arch dam is conducted through nonlinear endurance time analysis (ETA) of a typical arch dam. The $289 \mathrm{~m}$ high Baihetan arch dam in Southwest China (as a case study) is subjected to a set of 10 three-component endurance time acceleration histories (ETAHs) synthesised on the basis of the design site acceleration response spectrum to increasing peak ground acceleration (PGA). The effects of dam-reservoir-foundation interaction, radiation damping of infinite rock foundation, and nonlinearities of dam material and joint contact elements are considered. The indices to failure modes of damage propagation through the dam body and the deformation and joint opening beyond the limit states of the arch dam are identified. Dynamic responses, including deformation, joint opening, and damage distribution, are statistically analysed. The dispersion and correlation of indicators are analysed by employing the coefficient of variation and coefficient of correlation, respectively. The deterministic relationships between contraction joint opening, displacement, and damage volume ratio are obtained by using a multivariate fitting method. The results show that those failure indices have similar exponential trends, and seismic intensity parameters exert a significant influence on seismic response and damage under increasing PGA. The results of correlation and fragility analysis demonstrate that damage volume ratio and the sum of joint opening are consistent, which can provide a strong scientific basis for predicting earthquake damage.
\end{abstract}

\section{Introduction}

The seismic safety evaluation and performance analysis are the primary considerations when assessing the safety margin of a structure during an earthquake [1,2], and it also becomes one of the most significant concerns among hydraulic structural engineers worldwide. The dynamic response of a structure has uncertainty deriving from the randomness of ground motions, which will have an influence on the seismic capacity of the structure [3]. In particular, the damage response can reflect the characteristics of the damage distribution over time, resulting in eventual global instability; however, for an arch dam, challenges lie in the complexity of the dam-reservoir-foundation system and the extensive distributions of certain parameters so that specific failure modes are unclear in previous studies. This warrants further research to understand the severity of damage and realise fully the behaviours manifested in an arch dam subjected to earthquake loading.

Currently, several researchers investigated the input approach to an arch dam-foundation system [4] and explored the damage thereto by defining different dynamic responses [5] when subjected to strong ground motions. Various seismic evaluation indices were presented to estimate structural seismic performance accounting for structural nonlinearity, such as displacement, damage, and contraction joint opening indices [6]. Xu et al. $[7,8]$ performed the dynamic analysis of an arch dam to analyse the stress and contraction joint opening considering different input models. Hariri-Ardebili and Kianoush $[9,10]$ 
developed a seismic safety evaluation for arch dams and concrete gravity dams to simulate crack propagation behaviour. Ren et al. [11] proposed the use of a mixed finite element method for Shuanghe arch dam to simulate crack propagation therein and verify actual measured data with reasonable precision. Wang et al. [12, 13] developed a comprehensive procedure with which to analyse the seismic nonlinear behaviour of Pacoima and Dagangshan arch dams based on an arch dam-water-foundation rock system. Pan et al. [14] described a nonlinear damage system for featuring damage-crack behaviour under earthquake loading using both a massless foundation input model and a viscousspring boundary model. Other studies (Karalar and Cavusli [15-19], Kartal et al. [20, 21], and Demirtas et al. [22]) revealed the effects of ground motions on the seismic response and the damage assessment of structures. Most current studies only consider the dynamic response and damage extension under seismic ground motion, but research into the correlation of indicators remains sparse. In addition, the mechanism underpinning the dynamic behaviour of an arch dam is rarely analysed under strong ground motion and studies seldom consider both material nonlinearity and the verification of ground motion input to guarantee accuracy of the results.

Moreover, it is worth noting that many researchers paid more attention to seismic performance analysis methods considering the hazards of structural failure due to the complexity and bulk of the structure. In terms of structural analysis methods, incremental dynamic analysis (IDA) $[23,24]$, pushover analysis [25], and multiple stripe analysis [26] are widely used. Alembagheri et al. [27, 28] adopted the IDA method to analyse the damage propagation behaviour of both a concrete gravity dam and an arch dam and chose different indices to compare dynamic response requirements and structural capabilities with increasing earthquake intensity. Wang et al. [29] analysed a dynamic damage model of the Dagangshan arch dam-reservoir-foundation system to illustrate the damage characteristic and subsequently determined the seismic fragility curves under three limit states by using the IDA method. Pang et al. [30] evaluated the seismic resistance of high concrete face rockfill dams using the IDA method regarding different damage indices; however, it should be noted that these methods mainly established the relationship between dynamic responses and earthquakes at different intensities with high accuracy, but the computational burden and solution time were onerous. In the present research, this burden is a key issue considered while developing a method which can satisfy the demands imposed by analysis of different intensities and response spectra. Estekanchi et al. [31, 32] modelled a new seismic performance procedure called endurance time analysis (ETA) that can express different intensities and spectra to measure structural health. Valamanesh et al. [33] compared the seismic behaviour, dynamic responses, and crack tracing of Folsom and Koyna dams in the endurance time acceleration history (ETAH) input with real earthquakes to a reasonable degree of approximation. Hariri-Ardebili et al. $[34,35]$ used an ETA method for steel moment frames and concrete arch dam to assess structural seismic power effects in comparison to other methods to verify the effectiveness and precision of the ETA method. Other researchers (HaririArdebili et al. [36, 37], Riahi et al. [38, 39], and Estekanchi et al. [40]) also made many probabilistic damage analysis of structures by using the ETA method. The key to the ETA method is primarily to generate a set of ETAHs, which are selected as ground motion inputs indicating different levels of intensity. Due to the fact that time history in the ETA method corresponds to several different sets of the peak ground acceleration and response spectra, the amplitude modulation results can be obtained by a single endurance time acceleration history, which considerably saves computing time compared with the IDA method. Although the IDA method can more accurately describe the seismic performance of structures, the dramatically high computational effort leads to the limitation of the use of this method. In addition, the results of reference [39] show that the ETA method is a good tool to appraise IDA results with reasonably good accuracy using a few number of timehistory analyses. Furthermore, the scatter of results by the ETA method is considerably less than real earthquakes used in IDA analysis especially in the state of dynamic instability. Therefore, it can be seen that the ETA method is an effective method, with reasonable precision, and can thus be used as the input acceleration history of the base of dam in the present work.

In engineering practice, seismic acceleration histories are synthesised on the basis of the design site acceleration response spectrum. Seismic safety for dams can be derived on the basis of these artificial accelerograms inputs; however, the discrete nature of the dynamic results obtained by this method is key to the reliability of the method. In this work, a seismic performance ETA method suggests that different times correspond to the different acceleration response spectra via a scale factor, and the numerical optimisation method is adopted to generate ETAHs. The seismic fragility study of the Baihetan arch dam-reservoir-foundation system is presented using sets of ETAHs. The objective is the investigation of a case study that models the radiation damping of infinite rock foundation, contraction joint opening, and damage cracking of the concrete in the dam, to determine its seismic performance under different PGAs. The increasing intensity in earthquake ground motions is taken into account using the ETA method. The dam is modelled using finite elements along with its reservoir and foundation in 3D space. The plastic-damage model proposed by Lee and Fenves [41] is utilised for nonlinear analyses and determination of damage propagation in the dam body. Three components of ETAHs corresponding to the site response spectrum for increasing PGAs are simultaneously input. The dynamic responses of displacement, damage cracking, contraction joint opening, and so on for different failure modes are explored considering the randomness of ETAHs and the uncertainty of these responses of the dam, and these are analysed on the basis of their coefficients of variation and correlation. The relationship between each index is elucidated. 


\section{Seismic Response Analysis}

The objective of seismic response analysis of dams is to determine failure mode, to propose fragility indices, and to analyse probability distributions when dams are subjected to a given seismic intensity measure.

2.1. ETA Method. The PGA and acceleration response spectrum are two important factors for seismic intensity measure. ETA is a time history-based dynamic pushover procedure in which special predesigned intensifying acceleration functions are used for analysis and estimation of structural responses at various performance levels by using just a single analysis. Thus, an endurance time acceleration history (ETAH) generated by an unconstrained optimisation method can consider these two factors (PGA and acceleration response spectrum) simultaneously for different seismic intensity measures.

In the ETA method, an ETAH is used to replace a series of seismic histories with different acceleration peaks. As shown in Figure 1, the ETA method uses different interval times to satisfy the linear growth in design acceleration response spectrum with the factor $t / t_{\text {target }}$. The relationship among the target acceleration response spectrum $S_{\mathrm{aT}}(T, t)$, the target displacement response spectrum $S_{\mathrm{uT}}(T, t)$, and the codified design acceleration response spectrum $S_{\mathrm{aC}}(T)$ is

$$
\begin{aligned}
& S_{\mathrm{aT}}(T, t)=\frac{t}{t_{\text {target }}} S_{\mathrm{aC}}(T), \\
& S_{\mathrm{uT}}(T, t)=\frac{t}{t_{\text {target }}} S_{\mathrm{aC}}(T) \times \frac{T^{2}}{4 \pi^{2}},
\end{aligned}
$$

where $t_{\text {target }}$ is the target duration of ETAH, Tis the period of free vibration, $S_{\mathrm{aC}}(T)$ is the design maximum acceleration spectrum, and $S_{\mathrm{aT}}(T, t)$ and $S_{\mathrm{uT}}(T, t)$ are the target acceleration response spectrum and the displacement spectrum of interval times of ETAH from $0 \mathrm{~s}$ to $t$.

The ETAH is optimised by the ETA method, using an unconstrained optimisation formula in the time domain as follows:

$$
\begin{aligned}
\operatorname{minimize} F\left(a_{g}\right)= & \int_{0}^{T_{\max }} \int_{0}^{t_{\max }}\left\{\left[S_{a}(T, t)-S_{a T}(T, t)\right]^{2}\right. \\
& \left.+\alpha\left[S_{u}(T, t)-S_{u T}(T, t)\right]^{2}\right\} \mathrm{d} t \mathrm{~d} T,
\end{aligned}
$$

where $\alpha$ is the weighted parameter. Here, the displacement spectrum is not considered so $\alpha=0$. Figure 1 shows the incremental relationship of acceleration response spectrum to ETAH in the ETA method.

2.2. Seismic Dynamic Indices. In an ETA analysis, a series of strong ground motions are applied to the arch dam to assess the resistance of the structure. After applying increasing motion, the dam will change from a linear elastic state of stress to elastoplastic and ultimate collapse failure. The appropriate indices should be chosen to predict and monitor the crack propagation over its life-span in advance in case of sudden failure of the dam. In this way, the degree of damage and dynamic characteristic of the structure can be controlled within a certain range to ensure an adequate safety margin, maintain good performance, and achieve an efficient equilibrium state.

In general, arch dams mainly exhibit three failure modes: damage propagation through the dam body and deformation and joint opening beyond the limit states (Figure 2). Thus, this work mainly focuses on these three failure modes in terms of seismic fragility analysis. Furthermore, distinctive dynamic responses including damage volume ratio, contraction joint opening, and radial and vertical deformation are used as the appropriate indices for assessing the performance of an arch dam. The stream displacement at the crest centre is also used to evaluate the deformation, and the maximum and the sum of contraction joint opening are used to evaluate the joint opening. The damage volume ratios used to evaluate the damage from cracking are defined as

$$
\begin{aligned}
D_{g, 1} & =\frac{\sum_{e} \int_{v_{e}}\left(d_{t}\right) \mathrm{d} v_{e}}{\sum_{e} \int_{v_{e}} \mathrm{~d} v_{e}}, \\
D_{g, 2} & =\frac{\sqrt{\sum_{e} \int_{v_{e}}\left(d_{t}\right)^{2} \mathrm{~d} v_{e}}}{\sqrt{\sum_{e} \int_{v_{e}} \mathrm{~d} v_{e}}},
\end{aligned}
$$

where $d_{t}$ is the tensile damage at each individual element and $v_{e}$ is the volume of the element of the dam.

2.3. Probability Distributions. The fragility curves are assumed to take the form of a two-parameter lognormal distribution function [42-44]:

$$
P_{\text {LS }}(y)=\Phi\left[\frac{\ln (y / m)}{\beta}\right] \text {, }
$$

where $P_{\mathrm{LS}}(y)$ is the probability that a ground motion intensity $y$ will result in the limit state, $\Phi$ is the standard normal distribution, and $m$ and $\beta$ are the mean and logarithmic standard deviation of $y$, respectively. $m$ and $\beta$ are determined by the least squares regression.

2.4. Seismic Analysis Step. This investigation presents the seismic analysis of the Baihetan arch dam, a $289 \mathrm{~m}$ high double curvature arch dam in Southwest China. Figure 3 summarises the step in the analysis: modelling of the damwater-foundation system, synthesising ETAHs to the design site acceleration response spectrum and PGA for increasing seismic intensity measure levels, nonlinear seismic analyses, construction of fragility indicators and fragility curves, and analysing dispersion and correlation between indicators.

\section{Nonlinear Computational Model}

3.1. Constitutive Damage Model for Concrete and Nonlinear Contraction Joint. Based on the plastic-damage theory 


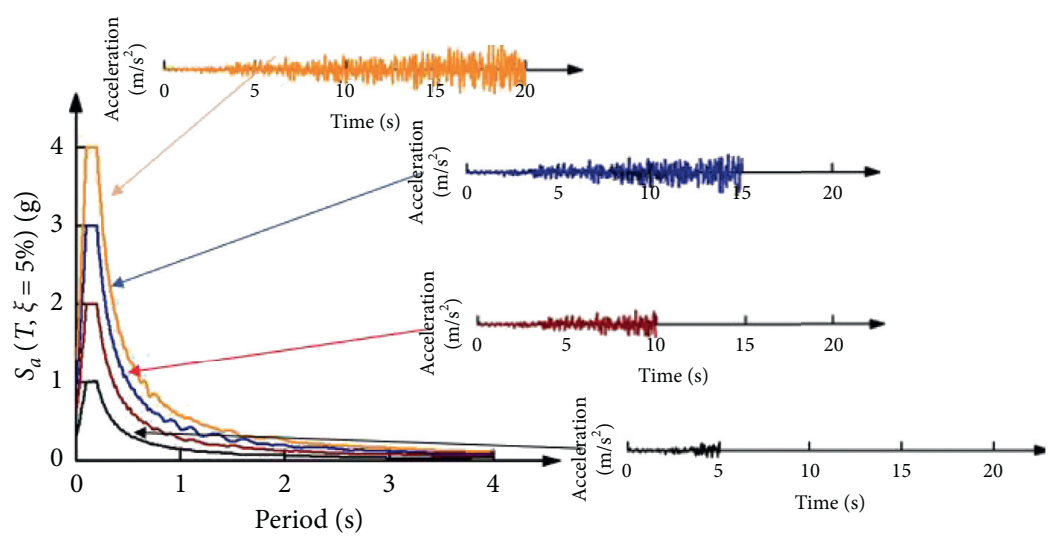

FIGURE 1: The incremental relationship of acceleration response spectrum to ETAH.

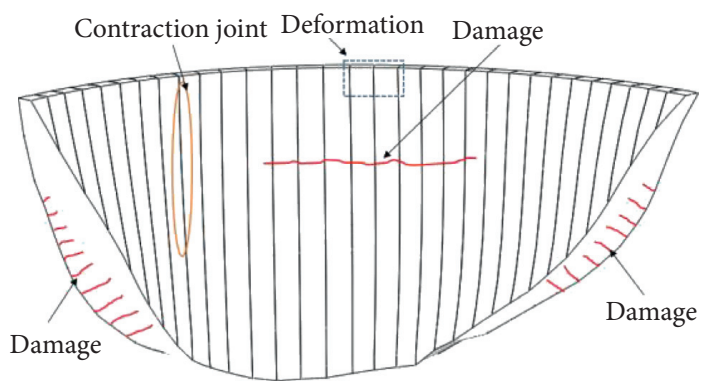

Figure 2: Typical failure modes for arch dams.

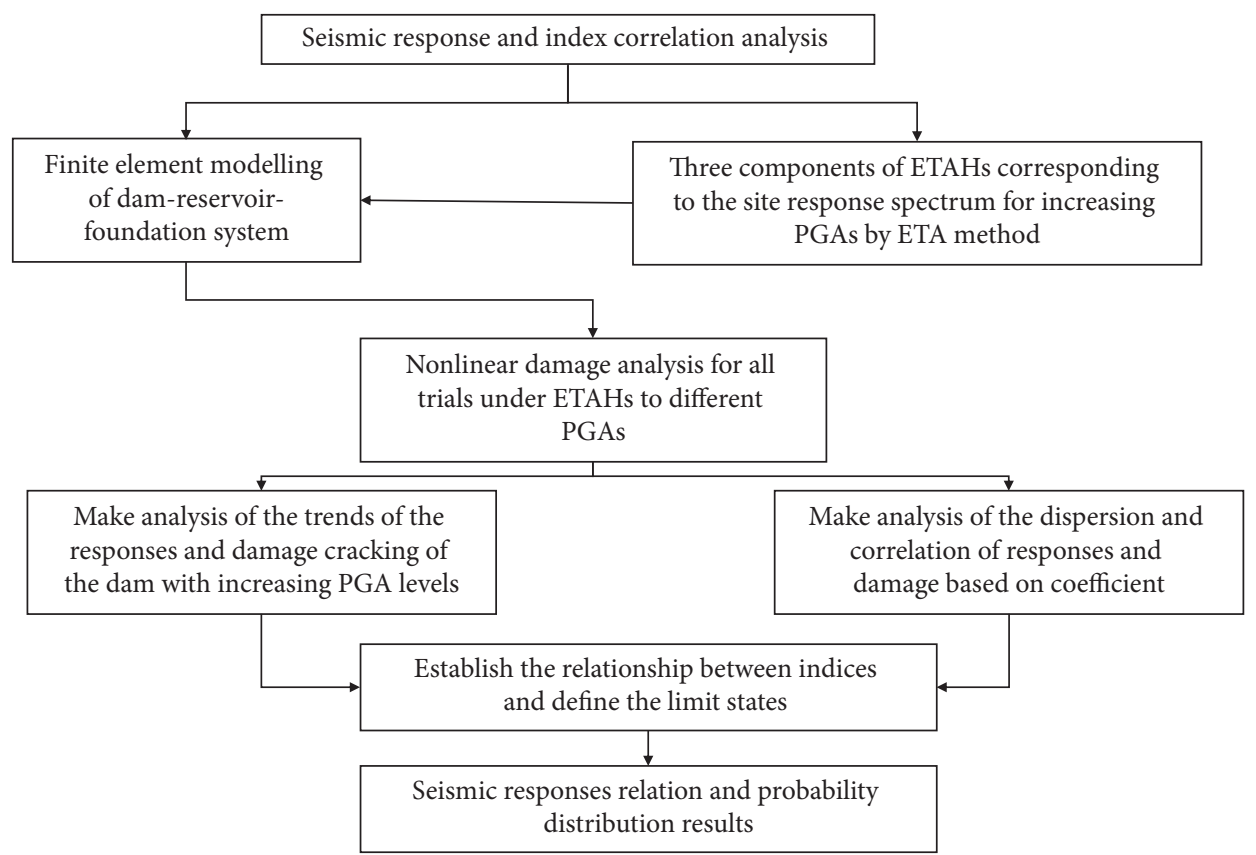

Figure 3: Flowchart: seismic response analysis.

proposed by Lee and Fenves [41], for concrete, the stressstrain relationship under uniaxial tensile load is as shown in Figure 4.
A contact boundary model is used to simulate the contraction joint [14, 45-47]. Figure 5(a) shows the master and slave surfaces in this model. Each node $M$ on the slave 


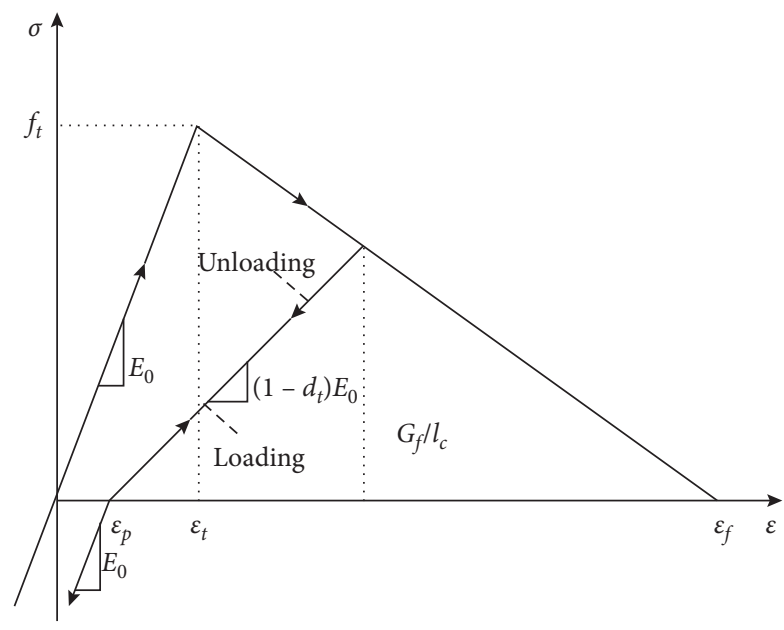

FIGURE 4: Concrete plastic-damage constitutive behaviour.

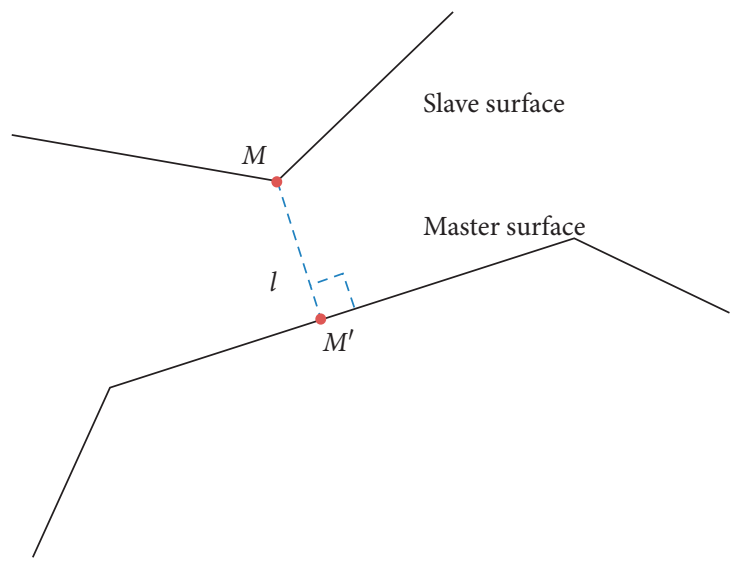

(a)

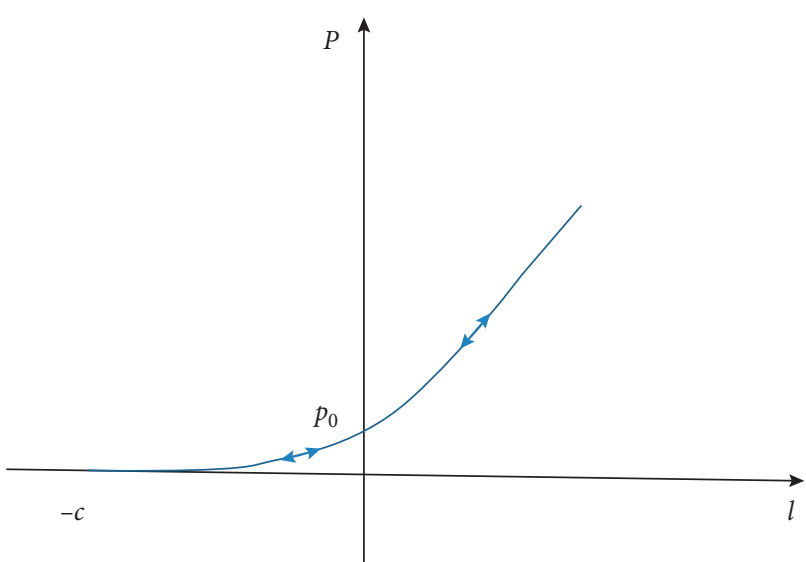

(b)

FIGURE 5: Contact boundary model for contraction joints: (a) relationship between elements of a contact pair; (b) pressure-overlap constitutive relationship.

surface is associated with a unique anchor point $M^{\prime}$ on the master surface. The relationship between the slave node $M$ and its corresponding anchor point $M^{\prime}$ is used to analyse the interaction between the slave and master surfaces. The tangential relative displacement $s$ is assumed to be zero. The tangential displacements between the two surfaces of the element are not allowed due to the shear key action at the contraction joints in the dam. The overlap of node $M$ normal to the master surface is denoted by $l$. Figure 5 (b) shows the normal pressure-overlap constitutive relation, which is used to prevent the slave node from overlapping with the master surface.

3.2. Viscous-Spring Artificial Boundary Condition Input. To simulate the radiation damping of the infinite mass rock, the dynamic artificial boundaries (such as transmission boundary, viscous boundary, and viscous-spring boundary) are used at the surface of the sufficient range foundation. Compared with the viscous boundary (also called quiet boundary) and the free-field input model generally used in software FLAC3D, the viscous-spring artificial boundary model, which not only can dissipate extroverted waves on the boundary but also simulates an elastic restoration effect of the faraway foundation, is generally employed in software ABAQUS. In addition, a typical numerical example is provided to illustrate the accuracy of the viscous-spring artificial boundary model.

\subsubsection{Viscous-Spring Artificial Boundary Condition Input} Method. The viscous-spring artificial boundary condition [8] is applied as a 3D space seismic input model. The seismic input method corresponding to the viscous-spring boundary is determined by several researchers, and the accuracy and applicability thereof are verified. With the help of the spring and the damping element in the finite element analysis software, springs and dampers are arranged in parallel in the normal and tangential directions of the artificial boundary nodes. The parameters of springs and dashpots of node $m$ on 
the viscous-spring artificial boundary are obtained by following equations for solving seismic input problems.

In the normal direction,

$$
\begin{gathered}
K_{n}=\alpha \frac{G}{r}, \\
C_{n}=\rho c_{p} .
\end{gathered}
$$

In the tangential direction,

$$
\begin{aligned}
& K_{s}=\alpha_{s} \frac{G}{r}, \\
& C_{s}=\rho c_{s},
\end{aligned}
$$

where $n$ and $s$ refer to the normal and tangential directions of the boundary plane, $K$ is the elastic stiffness of the spring, $C$ is the viscous damping, $G$ is the Lamé constant, $c_{p}$ is the propagation velocity of a $P$-wave, $c_{s}$ is the $S$-wave velocity, $\rho$ is the mass density, and $r$ is the distance from the wave source, which takes the approximate value of the perpendicular distance from the centre of the structure to the nodes on the artificial boundary. The recommended values of parameters $\alpha_{n}$ and $\alpha_{s}$ are 1.33 and 0.67 , respectively, according to Liu et al. [48].

Here, the explicit finite element method combined with time-domain integral analysis of a viscous-spring boundary is used. It is assumed that the displacement-time histories of plane $p$-wave and $s$-waves vertically incident at the bottom boundary are $u_{P}(t)$ and $u_{S}(t)$, respectively, and the equivalent force exerted on each artificial boundary node $m$ is calculated analytically according to the following formula and schematic diagram:

$$
\begin{aligned}
f_{m}(t)= & K_{m} u_{0}\left(x_{m}, y_{m}, z_{m}, t\right) \\
& +C_{m} \dot{u}_{0}\left(x_{m}, y_{m}, z_{m}, t\right) \\
& +\sigma_{0}\left(x_{m}, y_{m}, z_{m}, t\right),
\end{aligned}
$$

where $u\left(x_{m}, y_{m}, z_{m}, t\right)$ and $\sigma\left(x_{m}, y_{m}, z_{m}, t\right)$ denote the displacement and stress fields at the node $m$ in the artificial boundary model and $\sigma_{0}\left(x_{m}, y_{m}, z_{m}, t\right)$ is the stress field caused by the free wave field in the semi-infinite space.

\subsubsection{Verification of Viscous-Spring Artificial Boundary} Condition Input Method. MATLAB ${ }^{\mathrm{TM}}$ is used to realise a model incorporating viscous-spring boundary theory and the corresponding equivalent force in the direction at each artificial boundary node $m$. The rationality and correctness of the implementation of this viscous-spring boundary and the input method of ground motion herein are verified. It is worth noting that the appropriate time steps $\Delta t$ combined with finite element mesh size $\Delta x$ should be taken to ensure the stability and accuracy of the solution in numerical analysis. With regard to the near-field fluctuation problem, the use of the following formula is proposed [49]:

$$
\Delta x \approx\left(\frac{1}{8} \sim \frac{1}{10}\right) \lambda_{T}
$$

where $\lambda_{T}$ is the minimum wavelength.

In general, the time step is as follows:

$$
\Delta t=\frac{\Delta x}{c}
$$

where $c$ is the wave velocity of seismic propagation in the medium.

In this example, the $3 \mathrm{D}$ free-field model employing $\mathrm{SV}$ wave motion is used to verify the accuracy of the wave simulation process. To meet the requirements of finite element accuracy as mentioned above, a cubic solid element model with a side length of $180 \mathrm{~m}$ and an element size of $6 \mathrm{~m}$ is adopted. The time integral step $\Delta t=0.005 \mathrm{~s}$ for the seismic wave is used in this validation. The aforementioned model can meet the requirement of calculation accuracy. For the free-field model material, Young's modulus is $335 \mathrm{MPa}$, Poisson's ratio is 0.3 , and the density is $1800 \mathrm{~kg} / \mathrm{m}^{3}$. The six observed points of bottom and top surface are selected to extract the time history of displacement, as shown in Figure 6(a).

The time history of displacement $P(\tau)$ imposed on the bottom model is expressed as follows [50]:

$$
\begin{aligned}
P(\tau)= & 16 P_{0}\left[G(\tau)-4 G\left(\tau-\frac{1}{4}\right)\right. \\
& +6 G\left(\tau-\frac{1}{2}\right)-4 G\left(\tau-\frac{3}{4}\right) \\
& +G(\tau-1)],
\end{aligned}
$$

where $P_{0}=0.5 m, G(\tau)=\tau^{3} H(\tau), \tau=t / T_{0}, t$ is the load time duration, $H(\tau)$ is the Heaviside ladder function, and the total duration of the input pulse $T_{0}$ is $1 \mathrm{~s}$. The time history of the input Dirac displacement pulse function is shown in Figure 6(b).

The time history of displacement responses of observed points is depicted in Figure 7, and the numerical and analytical solutions of free-field objects are also compared. It can be seen that the comparison shows a good consistency between numerical and analytical solutions. The maximum displacement of top surface is almost twice that of the input displacement history, and the time delay effect can be properly reflected. Therefore, it can be concluded from the above that the compiled program can be further applied to the analysis of an arch dam.

3.3. Baihetan Finite Element Model and Seismic Input. The Baihetan arch dam (289 $\mathrm{m}$ in height and $715 \mathrm{~m}$ along the crest) is analysed: as shown in Figure 8, the maximum thicknesses at the crest and base of the dam crown cantilever are $14 \mathrm{~m}$ and $63 \mathrm{~m}$, and the corresponding water level varies from $545 \mathrm{~m}$ at base to $834 \mathrm{~m}$ at the crest of dam above sea level, respectively. The Baihetan dam-reservoirfoundation system is composed of an arch dam, a rock foundation with radiation damping. The far boundary of the foundation is at a distance from the dam of approximately 1.5 times the height of dam in all directions. The 


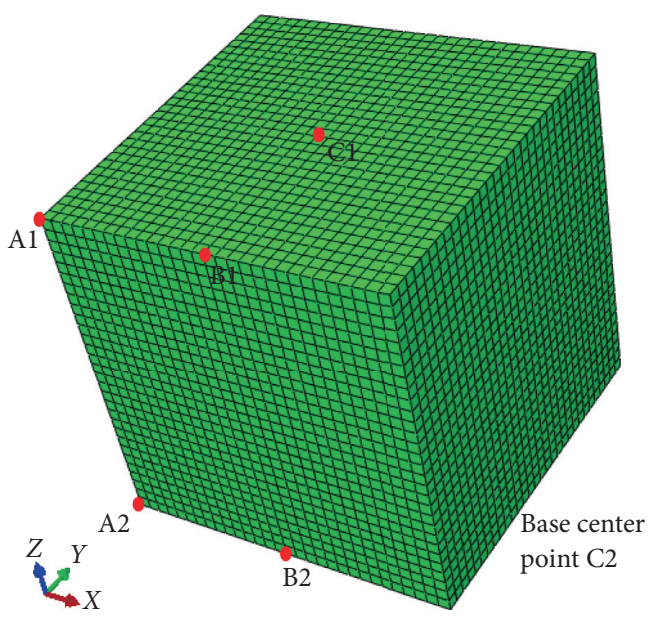

(a)

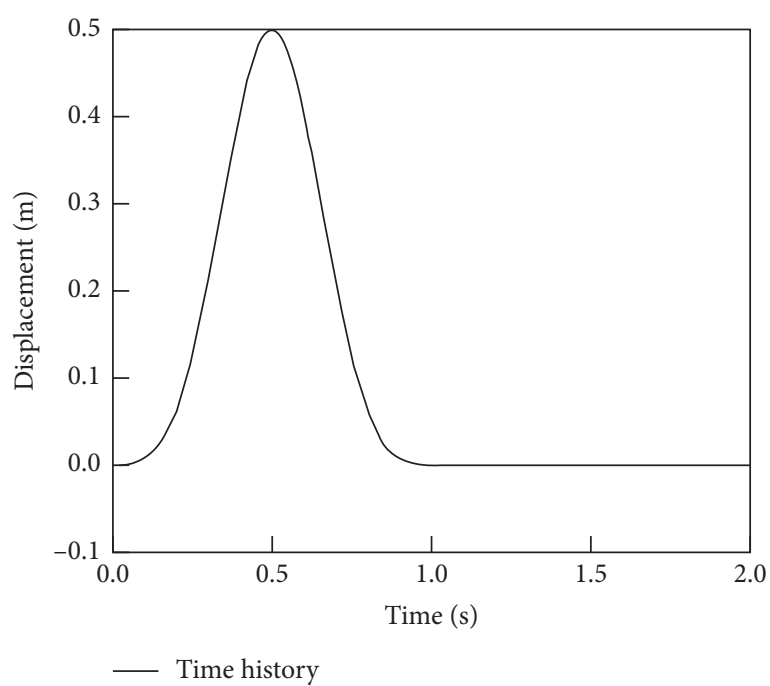

(b)

Figure 6: Verification of free-field employing a displacement pulse: (a) free-field finite element model; (b) time history of the input displacement pulse.

nonlinearities of the dam material and joint contact are also considered. The normal depth of reservoir water is $825 \mathrm{~m}$ above sea level. Finite element models, consisting of 25,776 hexagonal solid elements, are employed in the simulation of dam-foundation system. The hexagonal eight-node element is mainly used, while the prism element is used in the irregular part at the portions of the model. The arch dam body and foundation are discretized into 4,656 solid elements and 21,120 solid elements, respectively. To simulate the damage process, the average mesh size of the $3 \mathrm{D}$ dam body is approximately $0.6 \mathrm{~m}$. Moreover, to express the contact mechanism and simulate the possible opening and slippage of the dam, the 30 contraction joints are incorporated in the model, thus dividing the dam into 31 blocks (Figure 9). For each joint, the initial contact distance $c=0.005 \mathrm{~mm}$ and the pressure value $p_{0}=50 \mathrm{MPa}$ at the zero opening are selected based on Wang's article [46].

For the concrete in the dam, the density is $2400 \mathrm{~kg} / \mathrm{m}^{3}$, Young's modulus is $36 \mathrm{GPa}$, and Poisson's ratio is 0.167 . For the rock foundation material, the density, the elastic modulus, and Poisson's ratio are $2800 \mathrm{~kg} / \mathrm{m}^{3}, 26 \mathrm{GPa}$, and 0.24 , respectively. The tensile strength $f_{t}$ of the concrete used in the analysis is $3.6 \mathrm{MPa}$. The fracture energy $G_{F}$ is assumed to be $200 \mathrm{~N} / \mathrm{m}$ based on the parameters in $[10,51]$. The limiting tensile strain $\varepsilon_{f}$ is set to 0.0003 , and the characteristic length $l_{c}$ is $0.6 \mathrm{~m}$. The damping of the concrete dam system is assumed to be of Rayleigh type with a damping ratio of $5 \%$. The modal frequencies of the Baihetan model are listed in Table 1. According to the research of Hariri-Ardebili and Kianoush [9], the modal responses of arch dam-reservoirfoundation system are determined, which suggested the first and tenth natural vibration modes as the effective range. Then, the Rayleigh vibration parameters can be calculated from the first and tenth natural frequencies and damping ratio.
The main static load on the high arch dam is the selfweight of the dam body and the hydrostatic pressure. The sliding at the dam-foundation rock contact interface is not considered in the numerical analysis. The endurance time acceleration histories are generated by the ETA method. The viscous-spring artificial boundary is applied on the outermost boundary of the rock foundation. In the dynamic calculations, the interaction of the dam-reservoir, namely, the action of the hydrodynamic pressure due to earthquakes, is simulated by the Westergaard added mass technique [52] at the upstream surface nodes. The added mass of node $l$ on the upstream of dam during an earthquake is given as follows [53]:

$$
m_{\mathrm{ln}}=\frac{7}{8} \rho A_{1} \sqrt{H_{0} h}
$$

where $\rho$ is the water density, $H_{0}$ is the water depth of the reservoir, $h$ is the depth above node, and $A_{1}$ is the tributary area of node $l$ with $n$ being the normal direction of the curved surfaces containing node $l$.

The diagonal terms of added mass of node $l$ are then obtained as follows:

$$
\begin{aligned}
& m_{\mathrm{lx}}=m_{\mathrm{ln}} \cos (n, x), \\
& m_{\mathrm{ly}}=m_{\mathrm{ln}} \cos (n, y), \\
& m_{\mathrm{lz}}=m_{\mathrm{ln}} \cos (n, z),
\end{aligned}
$$

where $m_{l i}$ is the added mass component in $i$-indirection $(i=x, y, z)$ and $\cos (n, i)$ is the direction cosines of the normal direction $n$ of the curved surfaces.

Ten sets of ETAHs are synthesised based on the Baihetan arch dam site acceleration response spectrum: these have linearly increasing PGAs, as shown in Figure 10(a). Figure 10(b) shows the acceleration response spectra of 


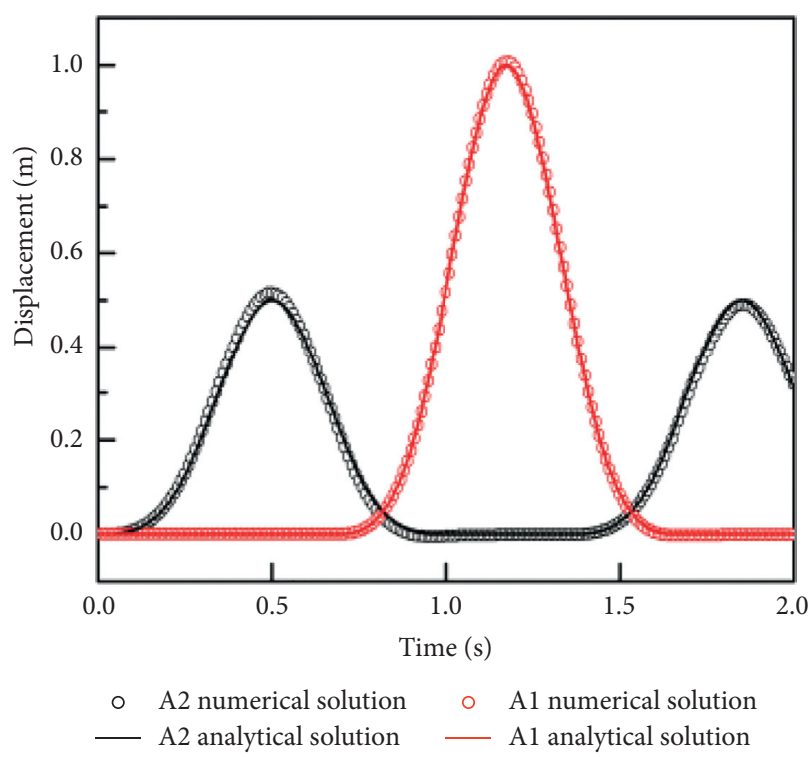

(a)

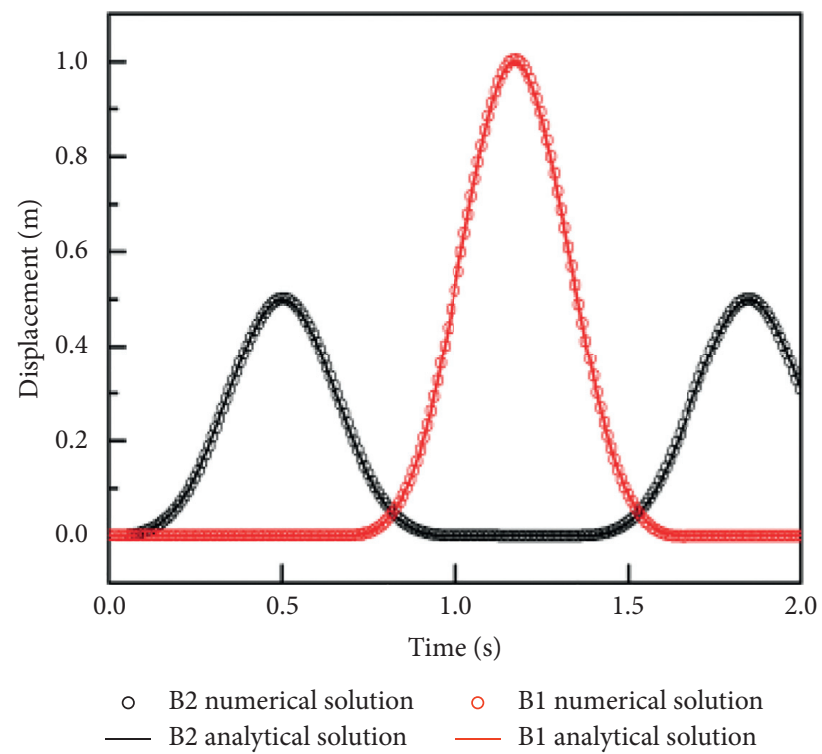

(b)

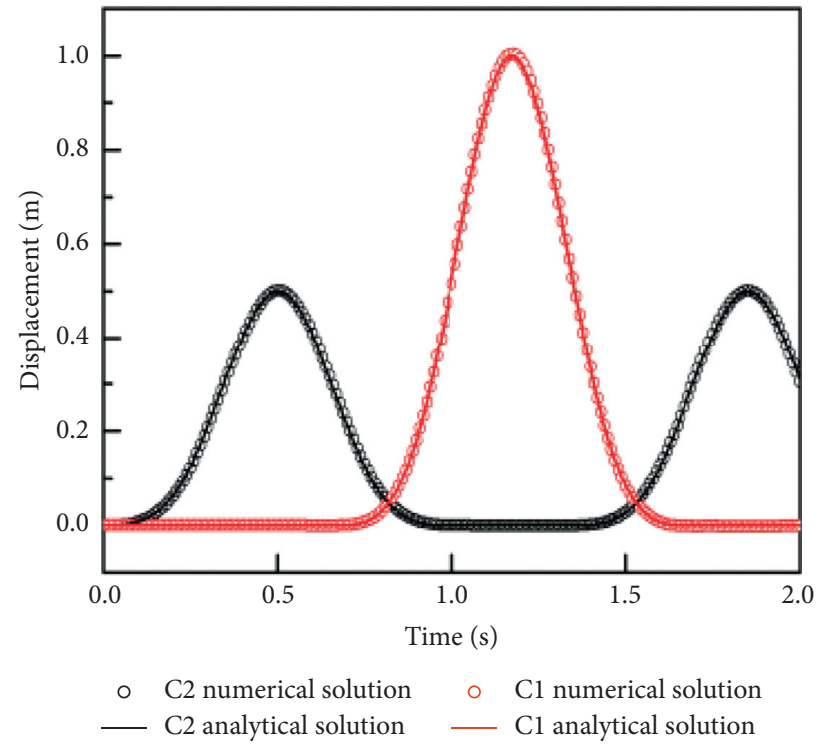

(c)

FIGURE 7: Free-field displacement-time history: (a) observation points A1 and A2; (b) observation points B1 and B2; (c) observation points $\mathrm{C} 1$ and $\mathrm{C} 2$.

three-directional ETAHs, in which the $X, Y$, and $Z$-directions represent the cross-stream, stream, and vertical directions, respectively. According to the current hydraulic standard, the peak acceleration in the vertical direction is two-thirds of that in the horizontal direction.

Figure 10 shows that the acceleration response spectrum for $0-5 \mathrm{~s}, 0-10 \mathrm{~s}, 0-15 \mathrm{~s}$, and $0-20 \mathrm{~s}$ follows a monotonic linear relationship which establishes that between the interval times of the ETAH and PGAs. In this model, the acceleration response spectrum for 0 to $20 \mathrm{~s}$ corresponds with a PGA of $1.2 \mathrm{~g}$, while the acceleration response spectrum from 0 to $5 \mathrm{~s}$ corresponds to $0.3 \mathrm{~g}$, and other acceleration response spectra follow the same trend with a uniform scale factor.

\section{Numerical Analysis of the Arch Dam}

\subsection{Damage Cracking Analysis}

4.1.1. Damage Distribution Analysis. The dynamic response of Baihetan arch dam-reservoir-foundation system under ten sets of ETAHs is analysed by the commercial finite element software ABAQUS. Figure 11 shows the damage profiles of the arch dam under four typical PGAs for two groups of ETAHs. When the PGA is $0.3 \mathrm{~g}, 0.6 \mathrm{~g}, 0.9 \mathrm{~g}$, and $1.2 \mathrm{~g}$, the damage distribution characteristics on the downstream face, upstream face, and crown cantilever are also shown in Figure 11, respectively. Considering that the compressive strength is significantly higher than the 


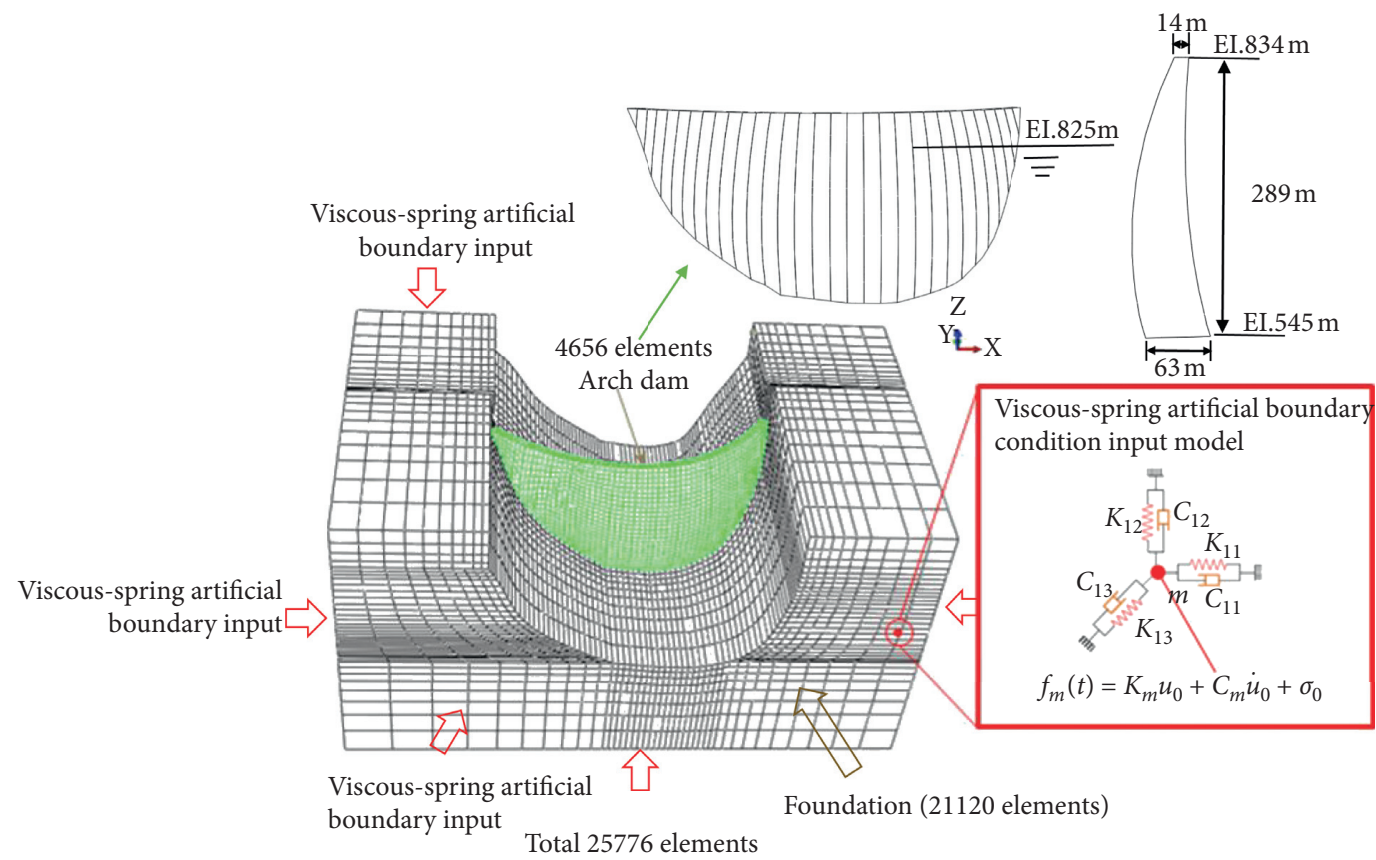

FIgURE 8: The Baihetan arch dam model.

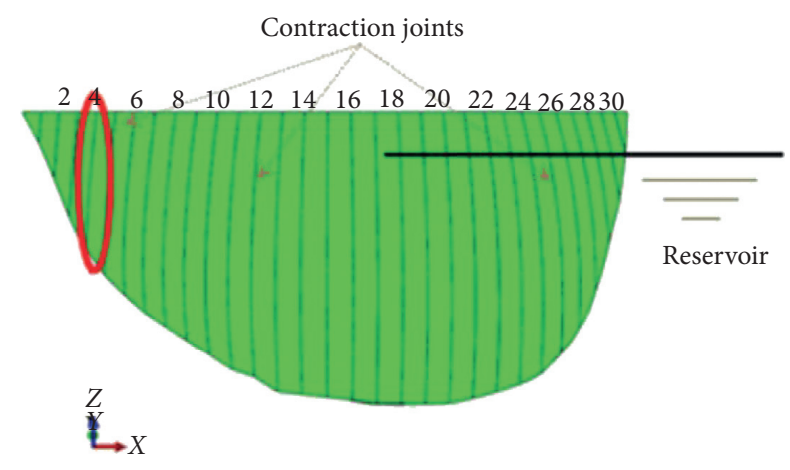

FIgURE 9: The contraction joint model.

TABLE 1: Dynamic characteristics of the Baihetan arch damfoundation system $(\mathrm{Hz})$.

\begin{tabular}{lccc}
\hline Mode & Frequency & Mode & Frequency \\
\hline 1 & 1.33 & 6 & 1.65 \\
2 & 1.35 & 7 & 1.97 \\
3 & 1.53 & 8 & 2.03 \\
4 & 1.55 & 9 & 2.04 \\
5 & 1.57 & 10 & 2.23 \\
\hline
\end{tabular}

tensile strength, only the tensile damage to concrete is considered [12]. The damaget in the graphics represents tensile damage of the arch dam, which is in correspondence with $d_{t}$ in Figure 4 . The results show that the damage to the arch dam increases gradually with increasing seismic intensity measure. The damage first appears at the bottom of dam on its upstream face and, subsequently, develops in the middle of the dam on its downstream face with increasing PGA. The main region showing damage lies on the arch base surface. Moreover, the upper region of the downstream face, with its greater curvature, is more damage prone. In particular, as seen in Figure 11, even if the seismic intensity measure is the same, the damage distributions differ slightly because of the randomness of the ETAH; however, the overall damage distributions are similar.

4.1.2. Damage Indices Analysis. To quantify the degree of damage to the arch dam, two damage indices are calculated using equations (4) and (5), respectively. Figure 12 shows the maximum, minimum, mean, and mean \pm standard deviation (SD) of the two damage indices. Figure 12 shows that the two damage indices have a cumulative effect and follow similar exponential evolutionary trends, suggesting that these damage indices share a certain equivalence. The data show that damage indicator $D_{g, 1}$ is more sensitive to seismic intensity measure than $D_{g, 2}$. Thus, $D_{g, 1}$ is the better indicator, and the SDs are approximately $50 \%$ and $25 \%$ of the means of the two damage indices at $10 \mathrm{~s}$ and $20 \mathrm{~s}$, respectively. This suggests that the discreteness of these damage indices will rapidly decline at a large seismic intensity measure.

\subsection{Deformation Analysis}

4.2.1. Deformation Distribution Analysis. In the numerical analysis of this arch dam, deformation indices are selected as engineering demand parameters to evaluate better the seismic performance of the dam. The time history of the specified damage index can be recorded during ETA analysis. Numerically, to obtain the time history of deformation in the process, each indicator or response is transformed into the maximum absolute value during the time interval from 0 

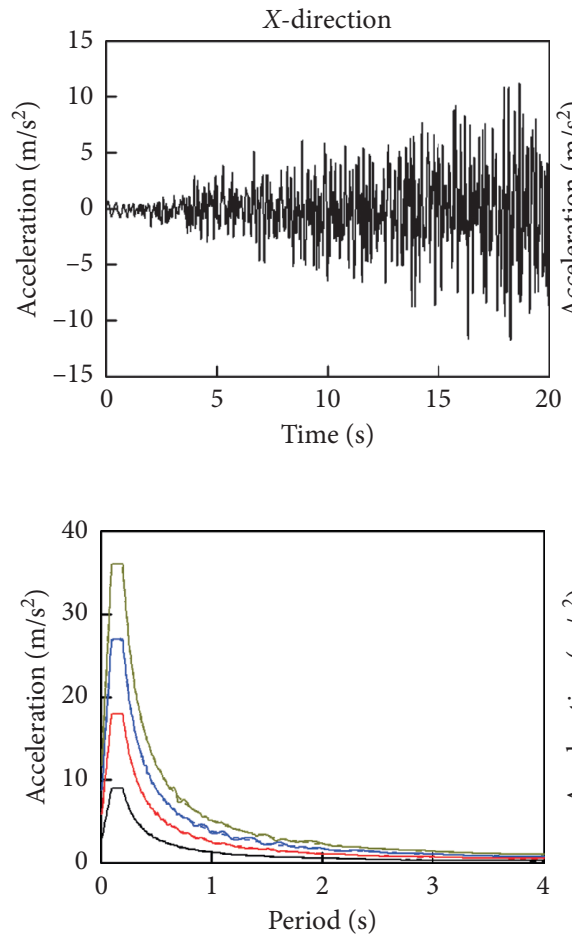

- - Target spect _ Response spe -rum of $0-5 \mathrm{~s} \quad$-ctrum of $0-5 \mathrm{~s}$

- - - Target spect _ Response spe -rum of 0-10s -ctrum of 0-10s

- - - Target spect __ Response spe -rum of $0-15 \mathrm{~s} \quad$-ctrum of $0-15 \mathrm{~s}$

- - Target spect _— Response spe -rum of $0-20 \mathrm{~s} \quad$-ctrum of 0-20s

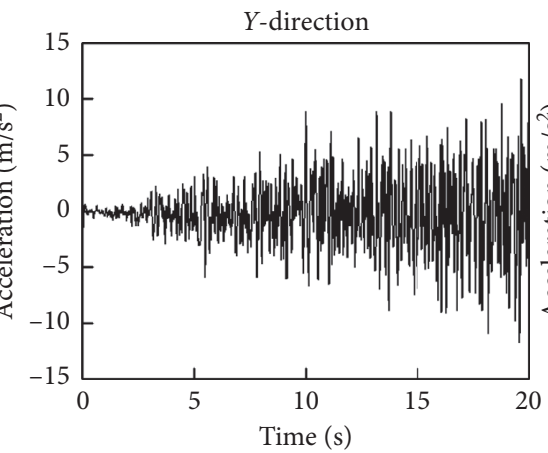

(a)

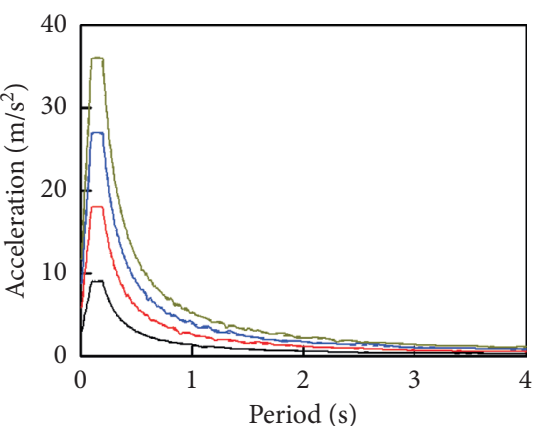

- - Target spect _ Response spe -rum of $0-5 \mathrm{~s} \quad$-ctrum of $0-5 \mathrm{~s}$

- - Target spect _ Response spe -rum of 0-10s -ctrum of 0-10s

- - - Target spect _ Response spe -rum of $0-15 \mathrm{~s} \quad$-ctrum of $0-15 \mathrm{~s}$

- - - Target spect _ Response spe -rum of 0-20s -ctrum of 0-20s

(b)
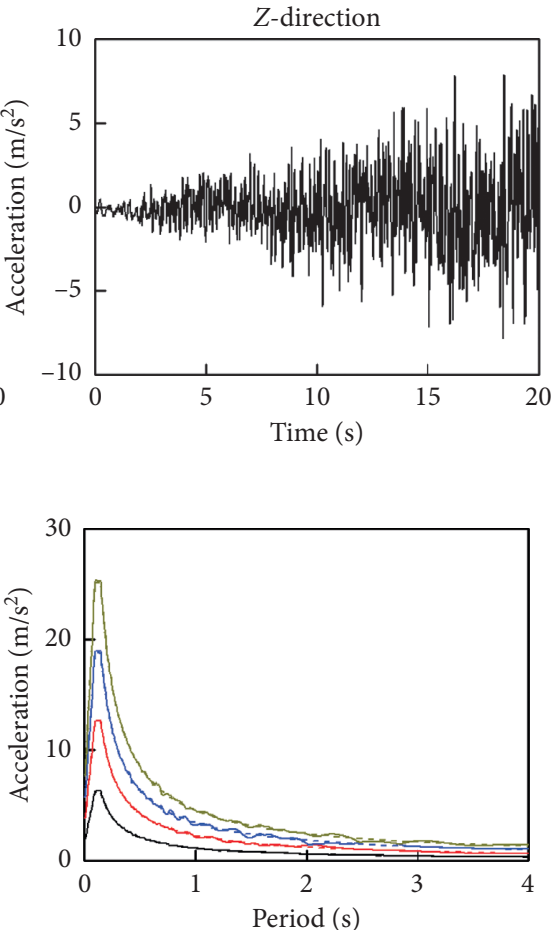

- - - Target spect _ Response spe -rum of $0-5 \mathrm{~s} \quad$-ctrum of $0-5 \mathrm{~s}$

- - Target spect _ Response spe -rum of 0-10s -ctrum of 0-10s

- - - Target spect _ Response spe -rum of $0-15 \mathrm{~s} \quad$-ctrum of $0-15 \mathrm{~s}$

- - - Target spect _ Response spe -rum of $0-20 \mathrm{~s} \quad$-ctrum of $0-20 \mathrm{~s}$

FIgUre 10: Typical (a) ETAHs and (b) acceleration response spectra within different interval times.

to $t$. The deformation indices can be defined by the following formula:

$$
\Omega(f(t)) \equiv \operatorname{Max}(\operatorname{Abs}(f(\tau): \tau \in[0, t])),
$$

where $\Omega$ is maximum absolute operator and $f(t)$ denotes the time history of the considered response.

Figure 13 shows the distribution of maximum stream deformation along the crest and the crown cantilever caused by 10 sets of ETAHs. The maximum, minimum, mean, and mean $\pm \mathrm{SD}$ are also plotted. As shown in Figure 13, the stream deformation response of the dam increases from the base to the crest as well as from the abutments to the centre. The peak values generally occur at the crest centre; therefore, the stream deformation at the crest centre can be used as an important fragility deformation indicator to different PGAs. Figure 13 also shows that the difference of stream deformation (the maximum, minimum, mean, and mean $\pm \mathrm{SD}$ ) in the downstream $(+)$ and upstream (-) direction increases from a PGA of $0.3 \mathrm{~g}$ to $0.6 \mathrm{~g}$ but less so from $0.6 \mathrm{~g}$ to $1.2 \mathrm{~g}$. This suggests that the stream deformation is sensitive to initial damage cracking propagation in the dam.
4.2.2. Deformation Indices Analysis. The stream deformation at the crest centre is used as a fragility deformation indicator. Figure 14 shows the stream deformation at the crest centre (the maximum, minimum, mean, and mean $\pm S D$ in the downstream and upstream directions at different PGAs). From $0 \mathrm{~s}$ to $20 \mathrm{~s}$, the stream deformation at the crest centre in the downstream $(+)$ and upstream (-) directions increases in a quasilinear manner and the SD is approximately $60 \%$ of the means of the stream deformation at the crest centre from $10 \mathrm{~s}$ to $20 \mathrm{~s}$. This suggests that the discreteness of these stream deformation indices is relatively stable under a large seismic intensity measure.

\subsection{Joint Opening Analysis}

4.3.1. Joint Opening Distribution Analysis. Figure 15 shows the statistical distribution of the maximum of joint opening, which includes the mean, maximum, minimum, and mean \pm SD values for PGAs of $0.3 \mathrm{~g}, 0.6 \mathrm{~g}, 0.9 \mathrm{~g}$, and $1.2 \mathrm{~g}$. At a PGA of $0.3 \mathrm{~g}$, the $18^{\text {th }}$ and $24^{\text {th }}$ joints at the crest centre undergo the largest openings. The mean and maximum openings are approximately $0.3 \mathrm{~mm}$ and $1.9 \mathrm{~mm}$, 
DAMAGET

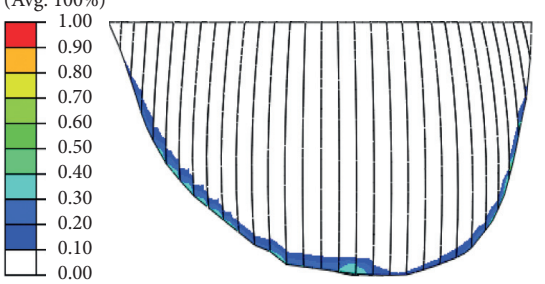

DAMAGET

(Avg: 100\%)

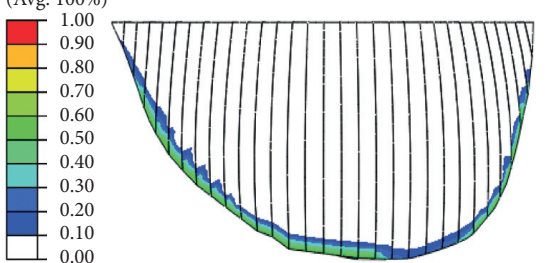

DAMAGET

(Avg: $100 \%$ )

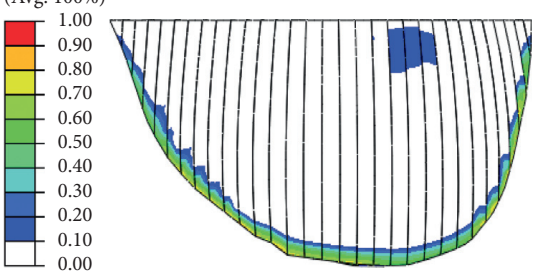

DAMAGET

(Avg: 100\%)
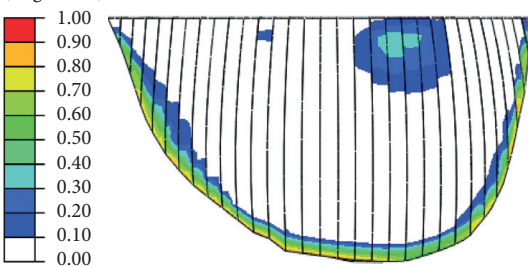

Upstream face
DAMAGET

(Avg: 100\%)

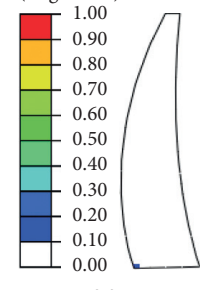

$0.3 g$

DAMAGET

(Avg: 100\%)

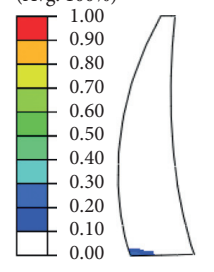

$0.6 \mathrm{~g}$

DAMAGET

(Avg: 100\%)

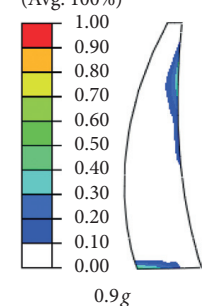

DAMAGET

(Avg: 100\%)

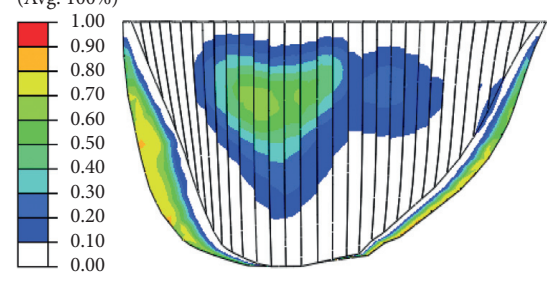

DAMAGET

(Avg: 100\%)

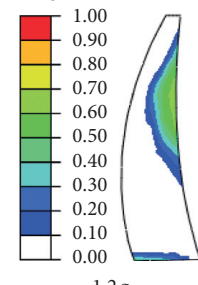

(Avg: 100\%)

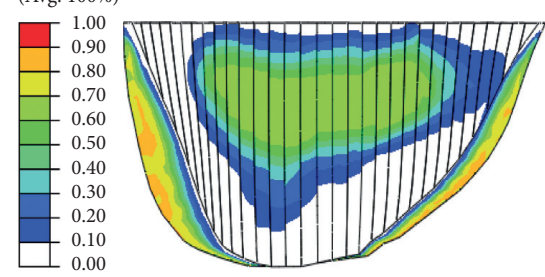

Crown cantilever

(a)
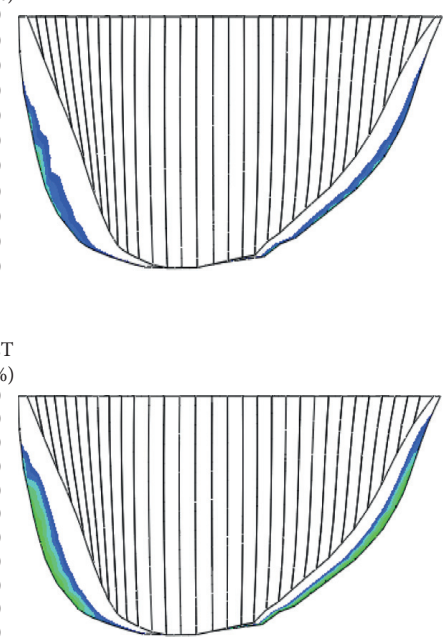

Downstream face

Figure 11: Continued. 

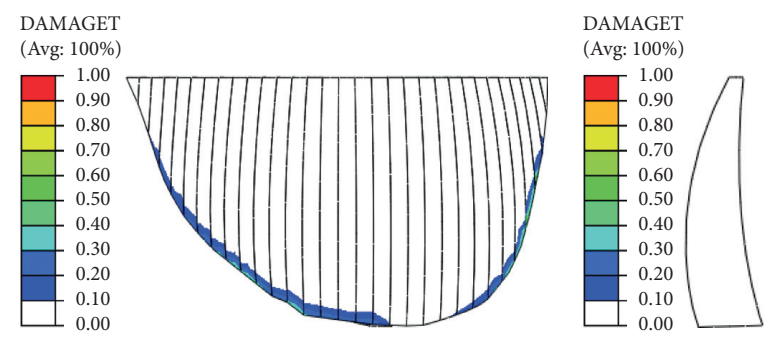

DAMAGET
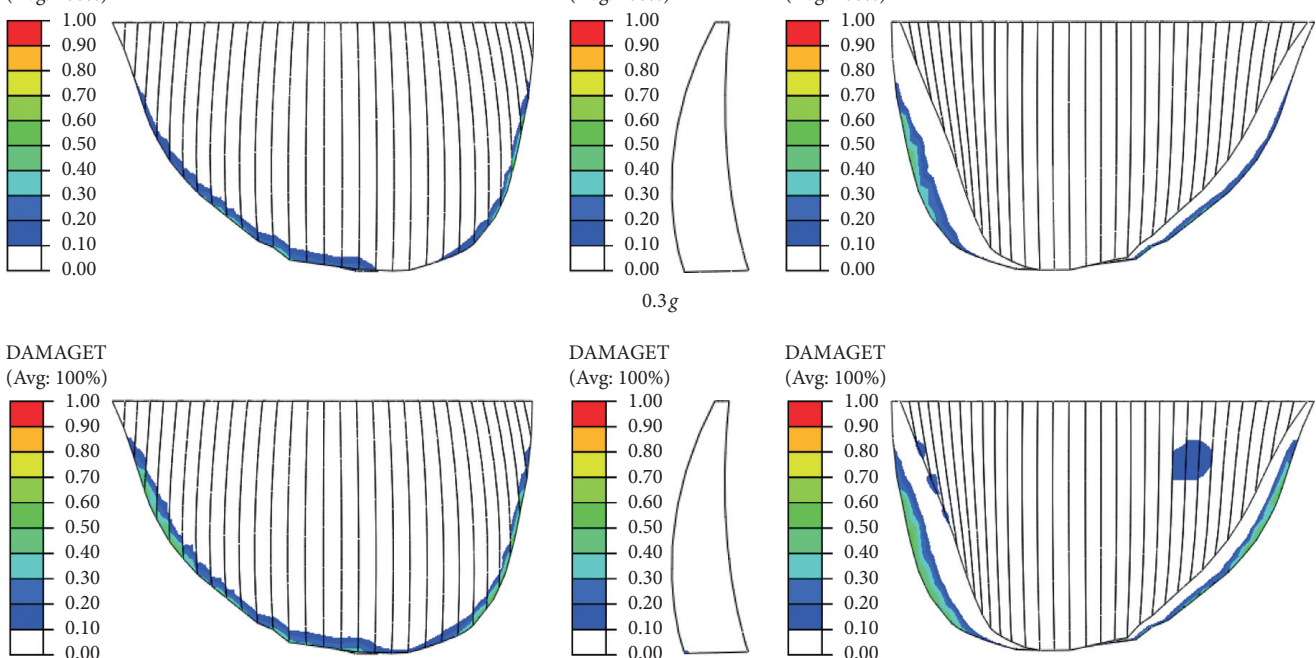

DAMAGET

(Avg: 100\%)

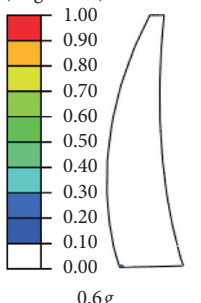

DAMAGET

(Avg: 100\%)
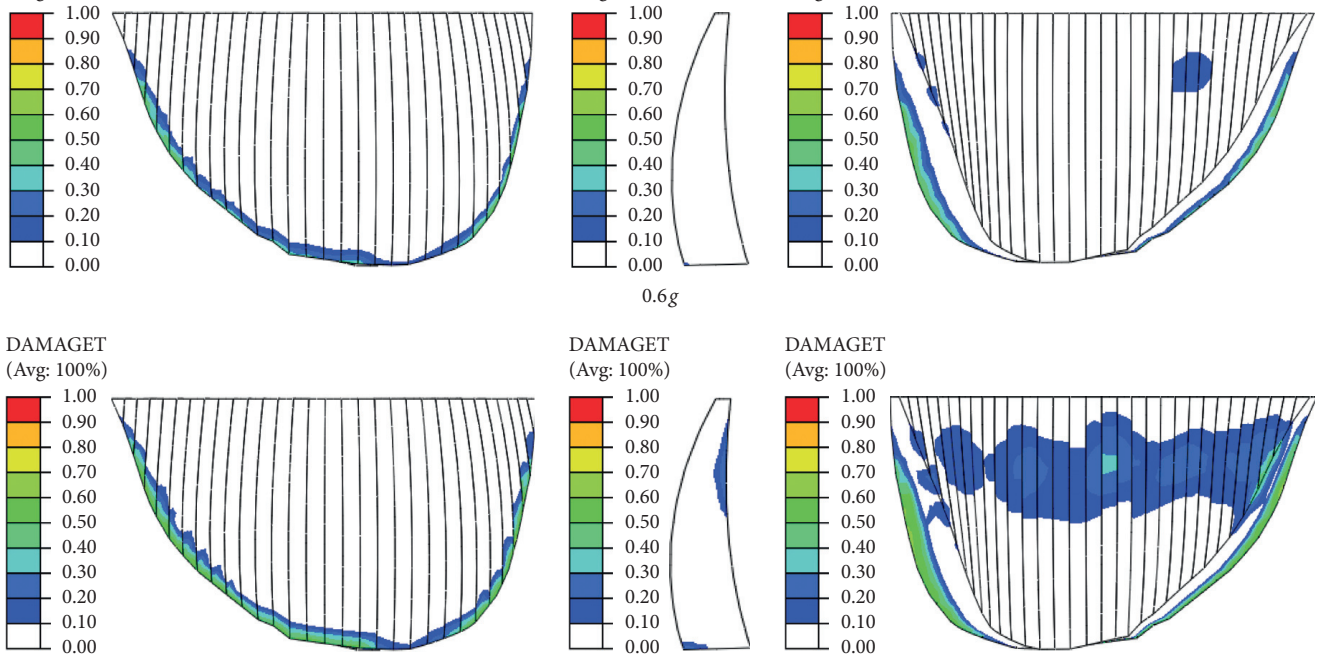

DAMAGET

Avg: 100\%)

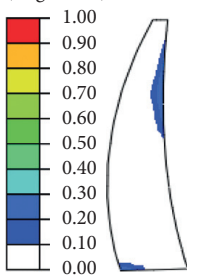

DAMAGET

(Avg: $100 \%)$

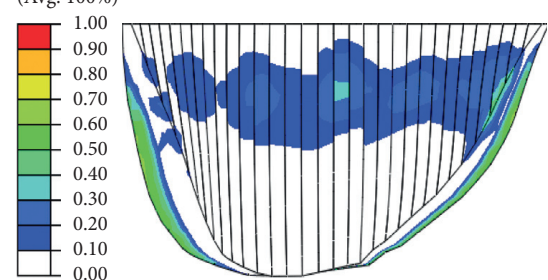

DAMAGET

(Avg: 100\%)

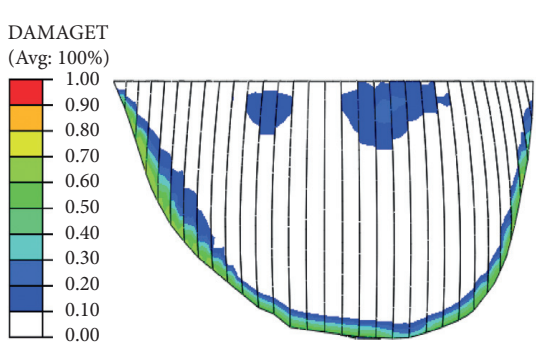

DAMAGET

$0.9 g$

$\begin{array}{r}0.10 \\ \hline\end{array} 0.00$

(Avg: 100\%)

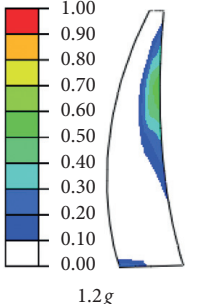

DAMAGET

(Avg: $100 \%$ )

Upstream face

Crown cantilever

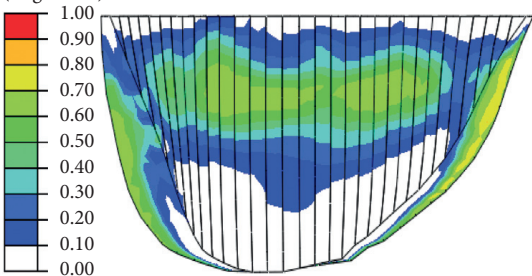

(b)

FIGURe 11: Damage distributions under typical PGAs for two cases of ETAH: (a) case no. 1; (b) case no. 3.

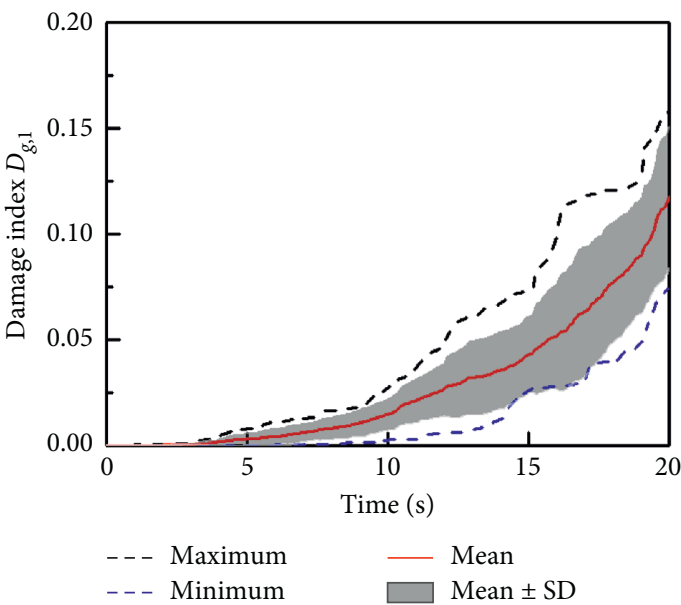

(a)

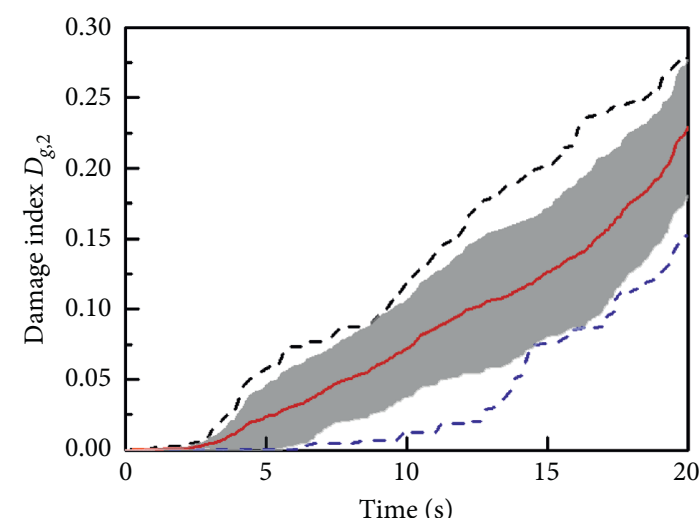

$\begin{array}{ll}--- \text { Maximum } & \text { Mean } \\ --- \text { Minimum } & \text { Mean } \pm \text { SD }\end{array}$

(b)

Figure 12: Fragility damage indices at different intensities: (a) $D_{g, 1}$; (b) $D_{g, 2}$. 

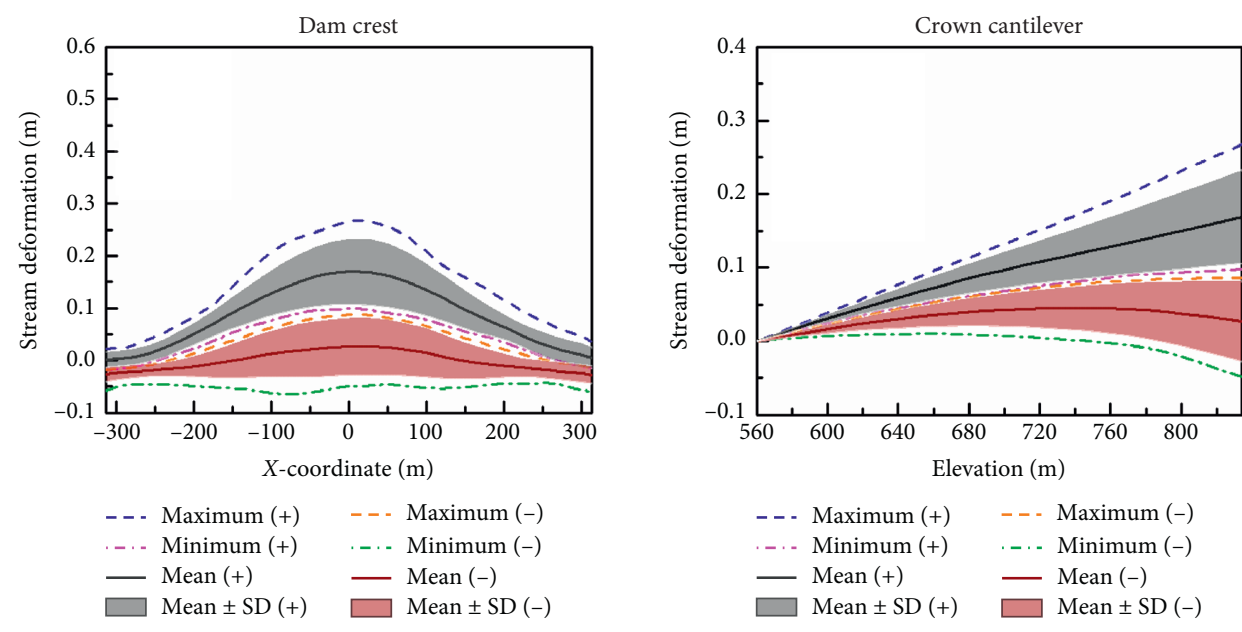

(a)
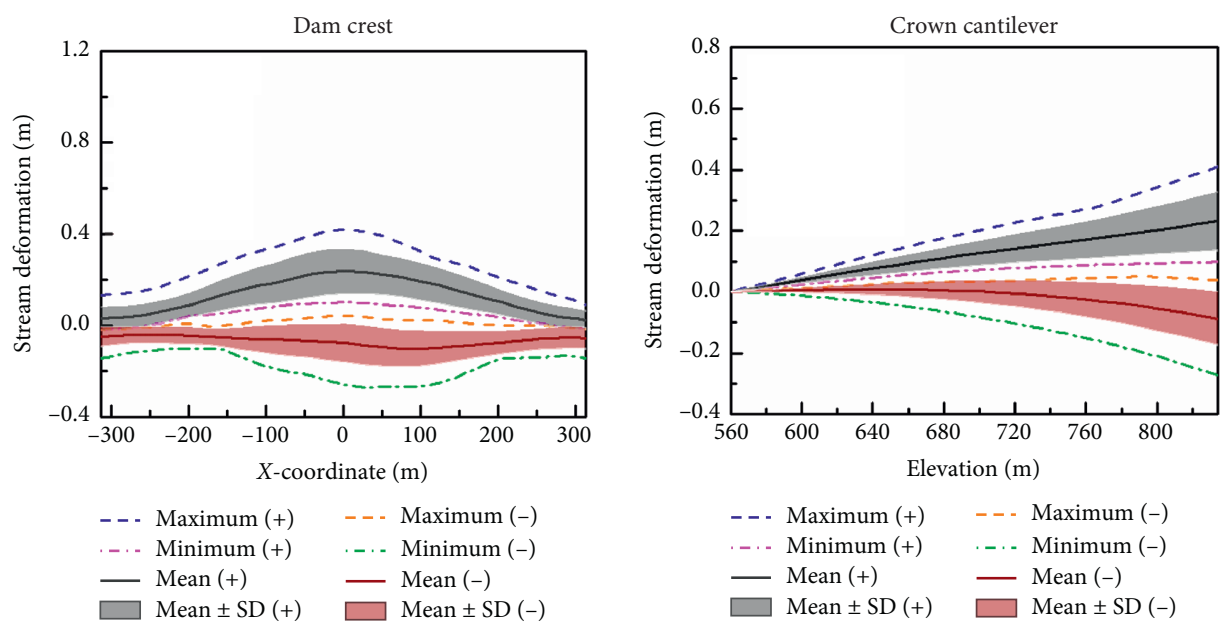

0.68
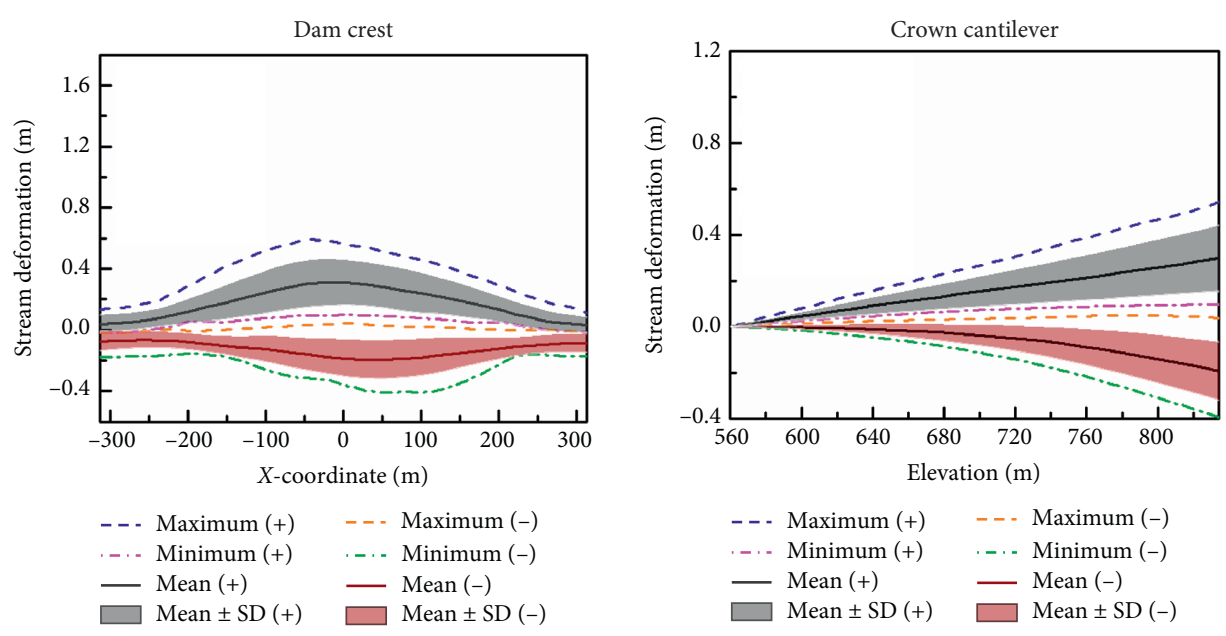

$0.9 \mathrm{~g}$

(c)

Figure 13: Continued. 

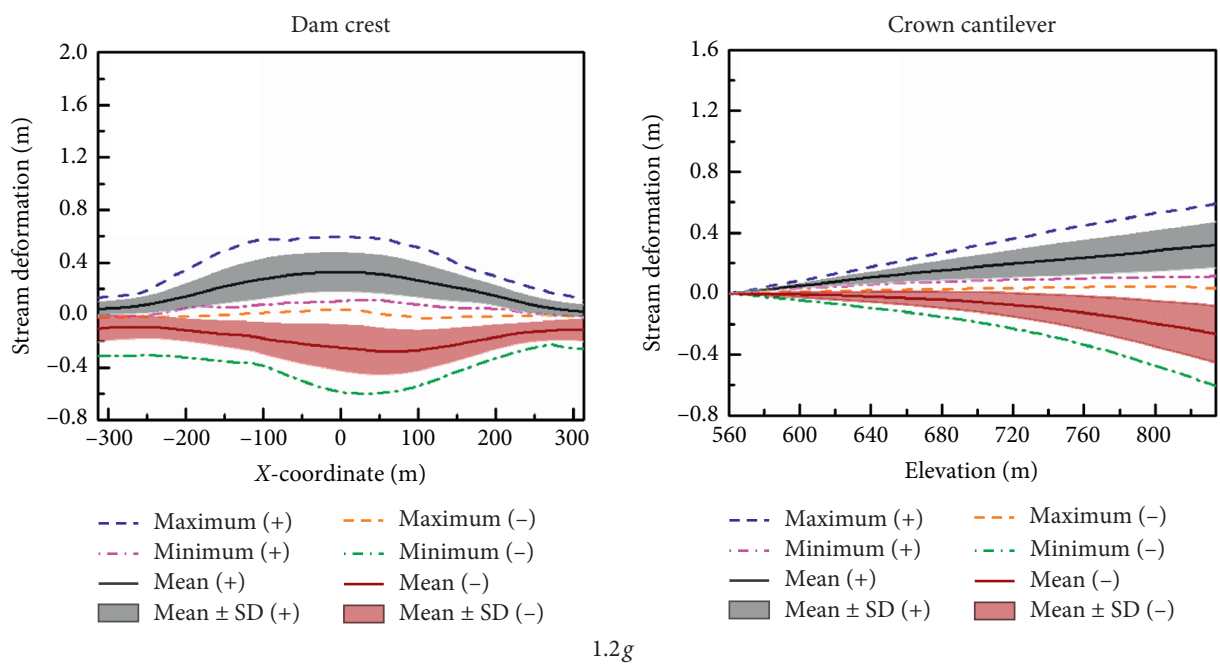

(d)

FIgURE 13: Distributions of stream deformation along the crest and the crown cantilever at different PGAs.

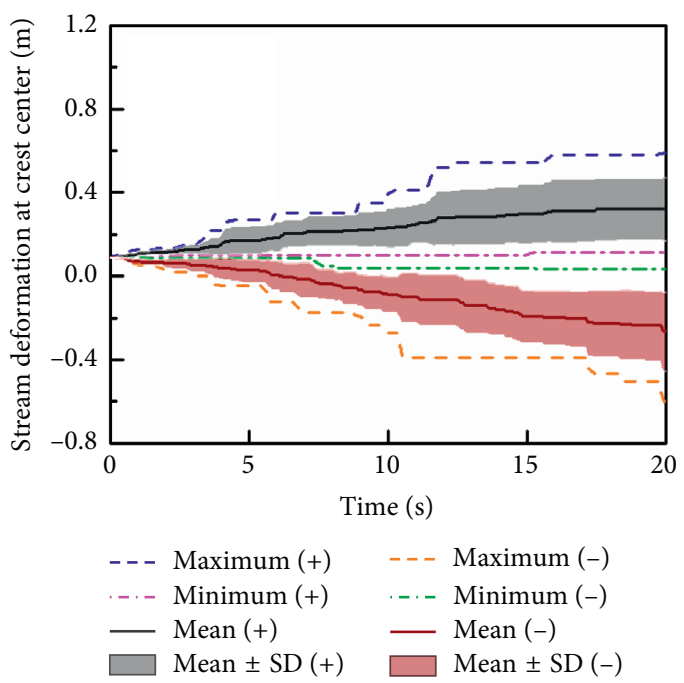

Figure 14: The stream deformation at the crest centre under earthquakes of different intensities.

respectively. At a PGA of $0.6 \mathrm{~g}$, as the PGA increased, the third joint near the left abutment and $18^{\text {th }}$ joint approximately at the crest centre both undergo large opening displacement. The mean and maximum openings increase nearly five-fold, reaching approximately $4 \mathrm{~mm}$ and $20 \mathrm{~mm}$, respectively. At a PGA of $0.9 \mathrm{~g}$, the third joint near the left abutment, $28^{\text {th }}$ joint near the right abutment, and $18^{\text {th }}$ joint at approximately the crest centre all undergo large opening displacements. The mean and maximum openings increase nearly four-fold, reaching approximately $15 \mathrm{~mm}$ and $62 \mathrm{~mm}$, respectively. At a PGA of $1.2 \mathrm{~g}$, the distributions are similar to those at $0.9 \mathrm{~g}$. The mean and maximum openings still increase slightly, reaching approximately $24 \mathrm{~mm}$ and $62 \mathrm{~mm}$, respectively, suggesting that when the PGA reaches a certain value, such as $0.9 \mathrm{~g}$ in this case, the joint opening will slowly increase and no obvious change in the distribution can be seen. In general, the peak joint openings occur at the crest centre and near the abutment.

4.3.2. Joint Opening Indices Analysis. Figure 16 depicts two joint opening indices the maximum of the joint opening (MJO) and the sum of the joint opening (SJO) that include the mean, maximum, minimum, and mean $\pm \mathrm{SD}$ values. Figure 16 shows that the two joint opening indices follow similar exponential evolutionary trends. This suggests that these joint opening indices also share a certain equivalence. The scatter is more significant than that of the deformation indices and damage indices, as shown in Figure 16. Furthermore, the scatter of the MJO is more significant than that of the SJO, suggesting that the SJO is a better joint opening indicator: the SDs are approximately $90 \%$ and $30 \%$ of the means for the MJOs at $10 \mathrm{~s}$ and $20 \mathrm{~s}$ but approximately $75 \%$ and $30 \%$ of the means for the SJO at $10 \mathrm{~s}$ and $20 \mathrm{~s}$. This suggests that the discreteness of these joint opening indices will rapidly decline at large PGA.

\section{Correlation and Dispersion Analysis of Indicators}

5.1. Dispersion Analysis. To explore the relationship between the strong motion intensity parameters and the seismic resistance of this arch dam, ten sets of dynamic response curves corresponding to each PGA obtained by ETA numerical analysis are determined. The damage volume ratios ( $D_{g, 1}$ and $D_{g, 2}$ ), joint opening (SJO and MJO), and maximum deformation (MRD and MVD) are also selected in this study. MRD and MVD responses represent the maximum radial deformation and vertical deformation of the dam crest, respectively. Subsequently, the response curves are used in a spline interpolation method at each intensity measure. On the basis of ten groups of dynamic responses analysed by ETA, the median and mean values are calculated to represent the central tendency of the response indicators. 


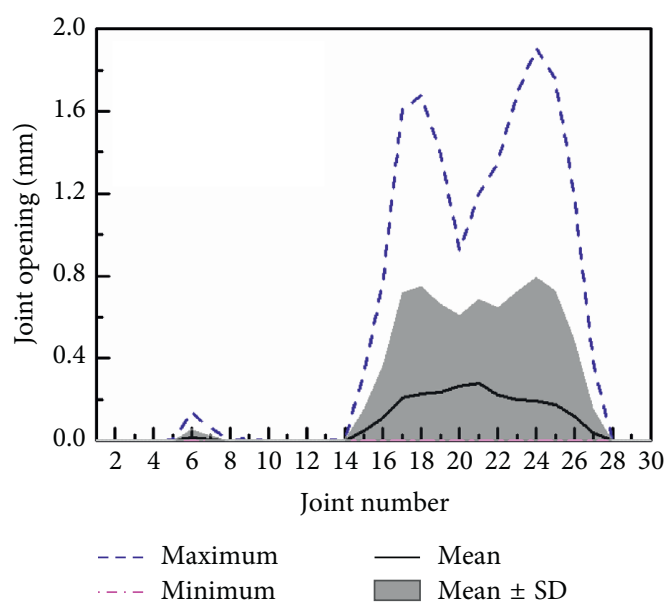

(a)

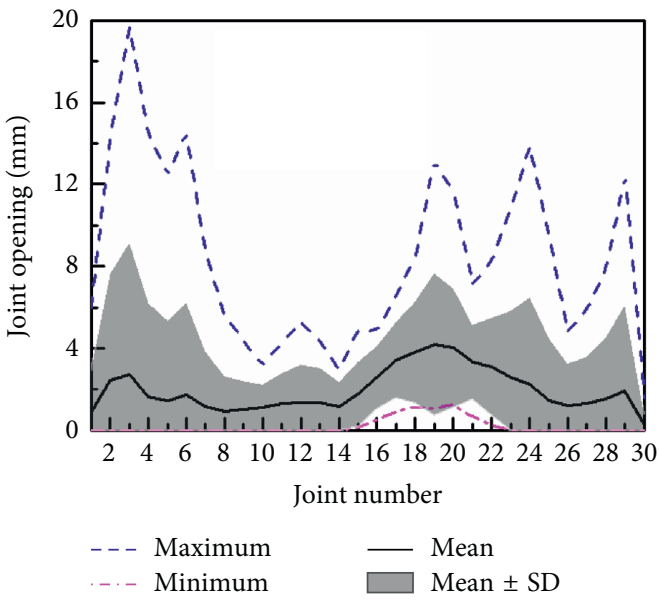

(b)

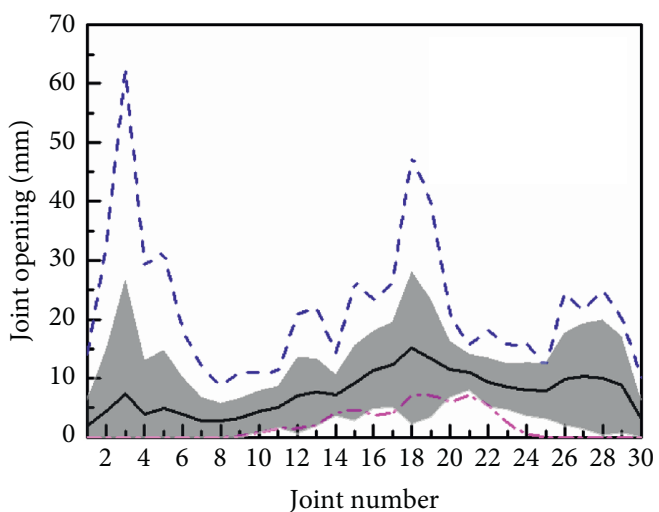

$$
\begin{array}{ll}
\text {-- } \text { Maximum } \quad \square \text { Mean } \\
\text {-.- Minimum } & \square \text { Mean } \pm \mathrm{SD}
\end{array}
$$

(c)

Figure 15: Continued. 


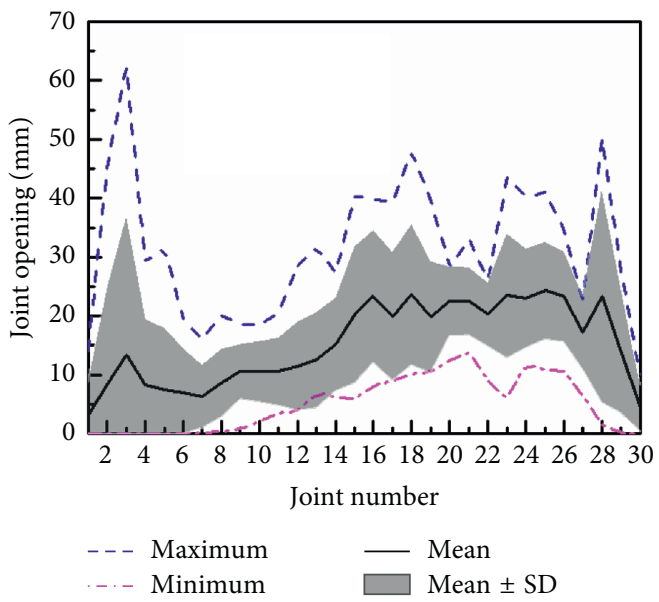

(d)

Figure 15: Joint opening distributions at different PGAs: (a) $0.3 \mathrm{~g}$; (b) $0.6 \mathrm{~g}$; (c) $0.9 \mathrm{~g}$; (d) $1.2 \mathrm{~g}$.

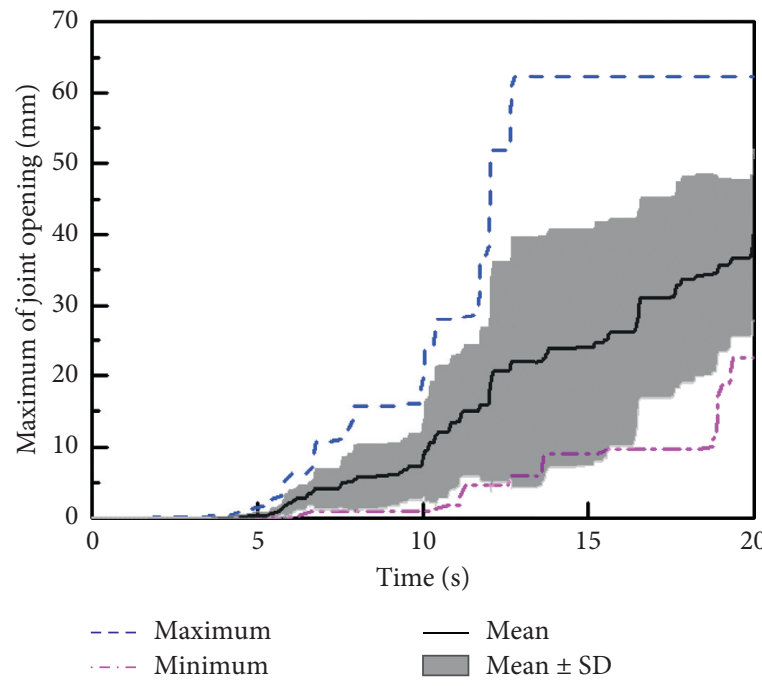

(a)

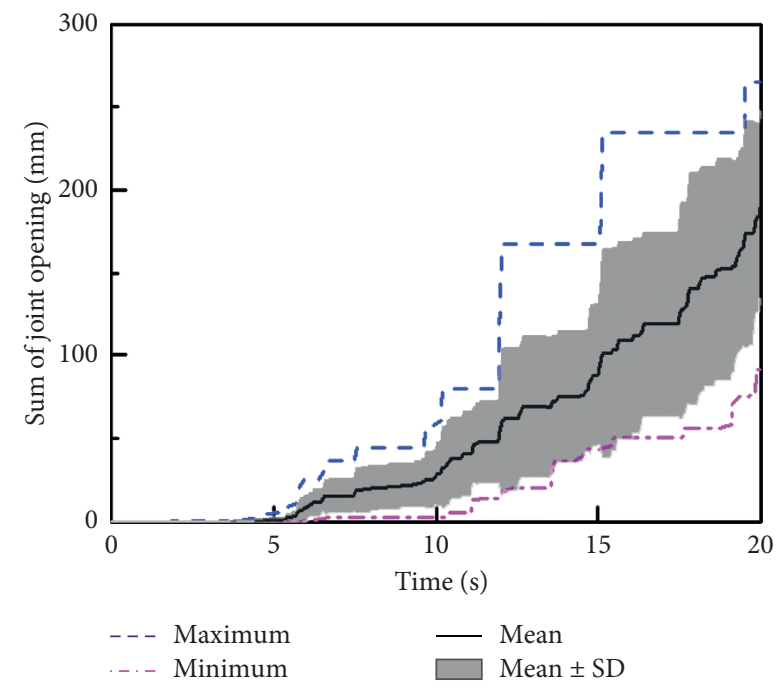

(b)

FIgURE 16: Fragility joint opening indices under different earthquake intensities: (a) MJO; (b) SJO.

The horizontal axis shows the damage indices in terms of the dynamic response, and the vertical axis denotes the PGA of the stream component which represents the intensity of ground motion. Meanwhile, the cumulative frequency curves (16\% and $84 \%$ fractiles) are also depicted in Figure 17.

It is inferred from Figure 17 that the mean value of the aforementioned indices has an increasing trend and most curves between the $16 \%$ and $84 \%$ fractiles show excellent consistency between each index. Three limit states of the arch dam can be determined by dynamic response indices. The tendency of median curve of various dynamic responses including damage volume ratio, joint opening, and deformation is analysed to determine three limit states. According to the mean joint opening value, there is little cracking up to $0.3 \mathrm{~g}$, indicating that the joint is not reflected in the nonlinear analysis nor is any such nonlinear resistance mobilised to maintain the stability of the dam. Meanwhile, slight damage occurs at the heel of the arch dam (Figure 11). Contraction joints are known to offer little resistance and will open and close repeatedly under strong ground motion. The joint opening can be used to describe the failure mode of an arch dam; therefore, when the intensity reaches $0.3 \mathrm{~g}$, there is no obvious opening of contraction joints, and the limit state can be defined as "minor" grade. Then, the slope and growth rate observed in the figure also show a significant effect of various indices, and the yield point also can be determined therefrom. The damage index, joints opening, and deformation increase significantly beyond approximately $0.7 \mathrm{~g}$, especially $D_{g, 1}$ and SJO. The downstream surface of the dam suffers a small range of damage. Thus, the mean value of indicators corresponding to the intensity of $0.6 \mathrm{~g}$ is regarded as "moderate" grade. An intensity of $1.2 \mathrm{~g}$ causes the 

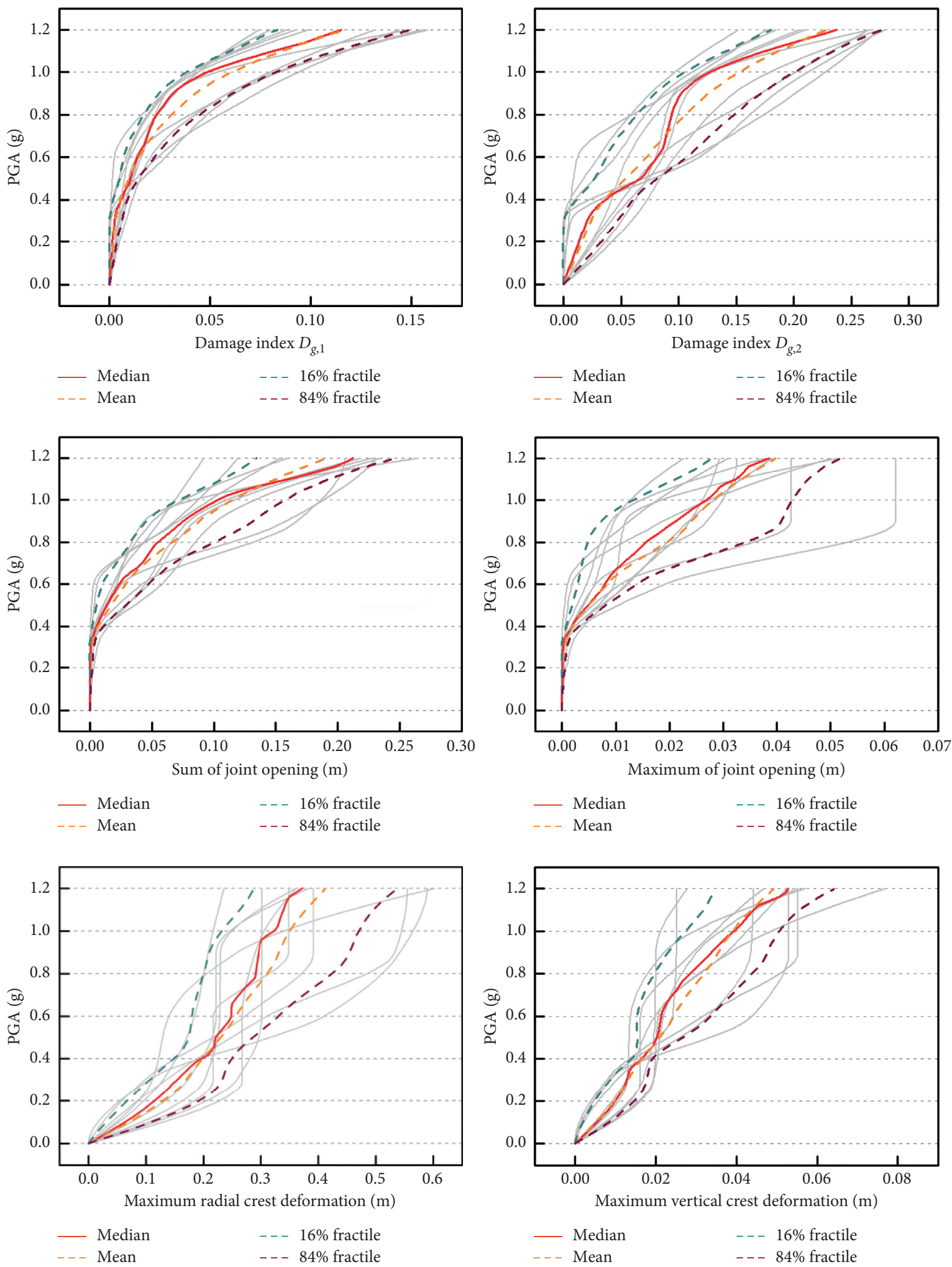

$---16 \%$ fractile
$---84 \%$ fractile

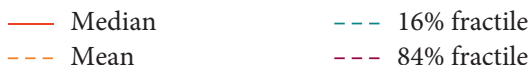

FIgURE 17: The relationship between damage indices and earthquake intensities.

most damage and is regarded as "serious" grade. To perform an accurate assessment of this arch dam, three limit states are proposed based on dynamic results and damage distribution.

The coefficient of variation of indices can be found from the variance and mean, as follows:

$$
\mathrm{CV}=\frac{\sqrt{D(X)}}{E(X)}
$$




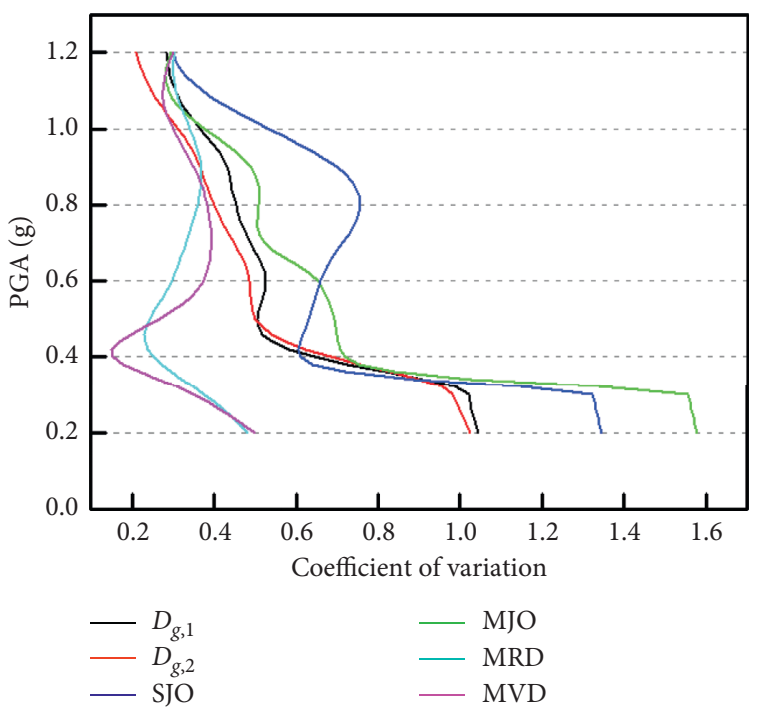

Figure 18: Dispersion curves at different earthquake intensities.

where $\mathrm{CV}$ is the coefficient of variation of indices, $X$ is response index, $D(\cdot)$ is the variance of the indices, and $E(\cdot)$ is the mean value thereof.

The dispersion curves of ETA responses (Figure 17) at different intensities are plotted in Figure 18. The degree of dispersion at each intensity measure can thus be deduced: a low dispersion can reflect the rationality of the optimal indices. The dispersion of the deformation index data is less than that of the damage index and less than that related to joint opening. In the state of minor, moderate, and serious grade damage, response results exhibit relatively little dispersion

5.2. Correlation Analysis between Different Indicators. To reveal the correlation between different indices, the correlation coefficient is calculated using the following formula:

$$
\rho_{\mathrm{XY}}=\frac{\operatorname{Cov}(X, Y)}{\sqrt{D(X)} \sqrt{D(Y)}},
$$

where $X$ and $Y$ are response indices, $\rho_{\mathrm{XY}}$ is the correlation coefficient, and $\operatorname{Cov}(X, Y)$ is the covariance of $X$ and $Y$.

Figure 19 shows the variation in correlation coefficient with ground motion intensity. The correlation coefficient of the identical category indices is strong and stable at each intensity level, such as $D_{g, 1}$ and $D_{g, 2}$, SJO and MJO, and MRD and MVD indices, suggesting similar dynamic characteristics among these indices. The correlation between $D_{g, 1}$ and joint opening is greater than that with $D_{g, 2}$, indicating that the sensitivity of $D_{q, 1}$ is generally good for contraction joints, and this can be used to evaluate the overall damage to the structure. For the comparison of deformation, vertical deformation has a better correlation with other indices than radial deformation. Compared with other indices, there is little difference between the sum of joint opening and the maximum of the joint opening, illustrating that both the overall evaluation index and local value can reflect the extension of transverse joints within the dam body. The damage index $D_{g, 1}$ correlates with joint opening indices, while $D_{g, 2}$ has a relatively good correlation with vertical deformation contrary to contraction joints indices at each level of intensity measure. In conclusion, damage and joint opening indices can be selected as effective indicators by comparing the coefficients thereof.

In practice, the measured response of the arch dam is mainly seen in terms of the deformation index (such as displacement and contraction joint opening), a damage index that can help the engineer to evaluate the overall degree of damage to the structure, but the damage index is difficult to detect in practice, so how to predict the damage index from the deformation index is a key problem that needs to be solved.

To demonstrate the previous research and establish the relationship between response indicators, the linear statistical curves and factors are modelled. The correlation coefficient between various indices is summarised in Table 2. As depicted, $D_{g, 1}$ has a remarkable effect on the SJO index in contraction joint opening, followed by that of the MVD index. The relationships between damage index and SJO index and MVD index are shown in Figure 20. The composite index using SJO and MVD indices is used to predict the damage index through multivariate fitting. In particular, the trend line and $R^{2}$ value in Figure 20 show that damage index $D_{g, 1}$ has a significant correlation with joint opening under a sequence of increasing intensity levels. In addition, $R^{2}$ for the composite index is 0.926 ; this is greater than that of each individual index $(0.906$ and 0.624) including the SJO and MVD indices, indicating that the comprehensive model containing SJO and MVD indices has a relatively good correlation with $D_{g, 1}$. The statistical formulae linking SJO, MVD, and the composite index are given in equations (18)-(20), respectively. In this way, the overall damage characteristics of the structure can be deduced by specific physical quantities such as the joint opening and maximum vertical deformation: 


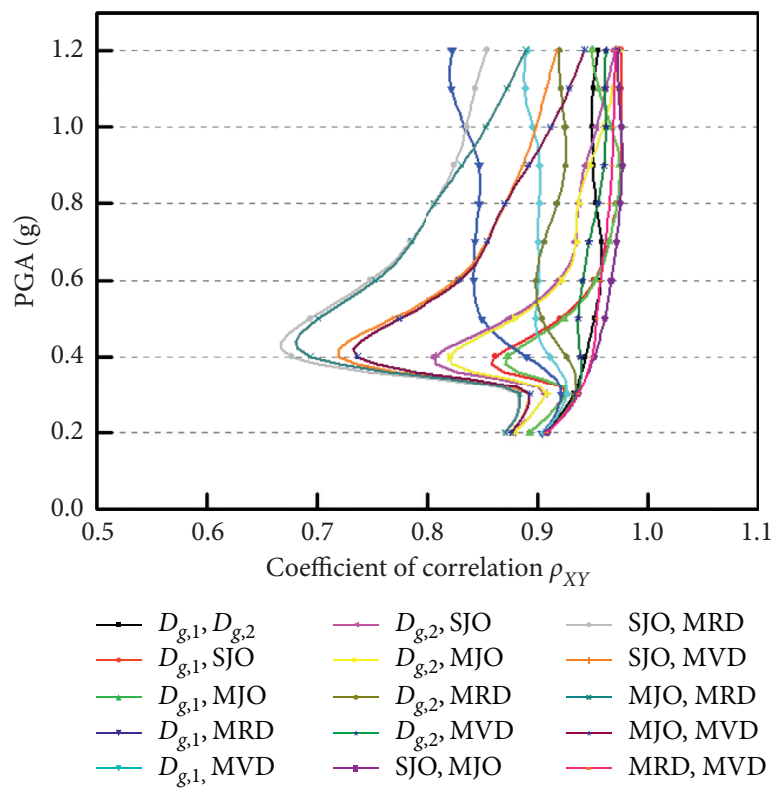

Figure 19: Coefficient of correlation at different earthquake intensities.

TABLE 2: Correlation between various indices.

\begin{tabular}{lccccc}
\hline Index & $D_{g, 1}$ & $D_{g, 2}$ & SJO & MJO & MRD \\
\hline$D_{g, 1}$ & 1.000 & 0.930 & 0.906 & 0.672 & 0.496 \\
$D_{g, 2}$ & 0.930 & 1.000 & 0.905 & 0.751 & 0.650 \\
SJO & 0.906 & 0.905 & 1.000 & 0.736 & 0.466 \\
MJO & 0.672 & 0.751 & 0.736 & 1.000 & 0.627 \\
MRD & 0.496 & 0.650 & 0.466 & 0.627 & 0.653 \\
MVD & 0.624 & 0.653 & 0.532 & 0.596 & 0.532 \\
\hline
\end{tabular}

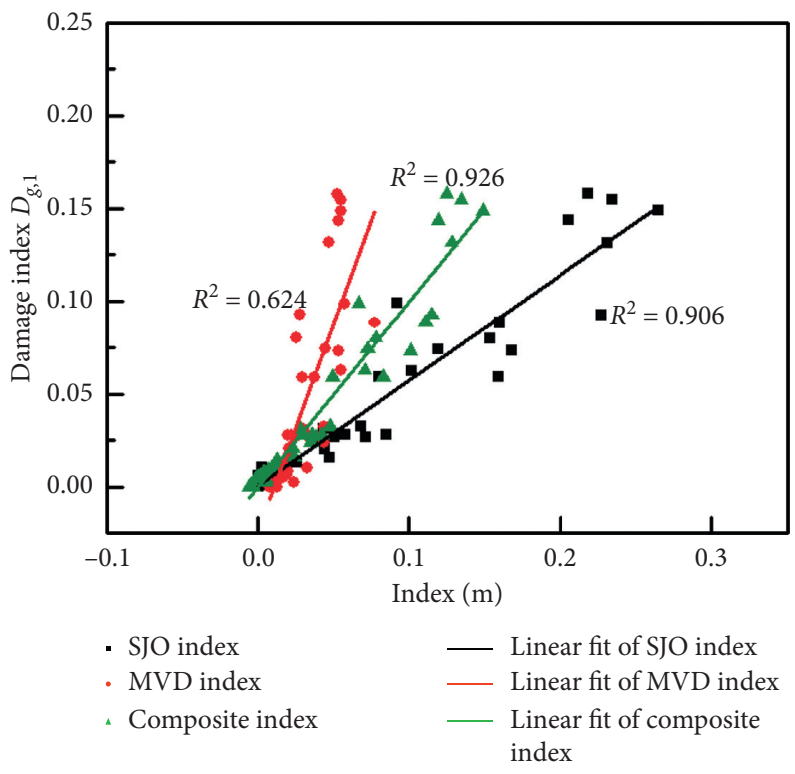

Figure 20: Regression lines for different indicators. 
TABle 3: Three limit state of arch dam.

\begin{tabular}{|c|c|c|}
\hline Level & Limit State & Description \\
\hline I & Minor & $\begin{array}{l}\text { The contraction joint may be opened, but with a small degree of opening that will have no additional impact on the } \\
\text { performance of dam }\end{array}$ \\
\hline II & Moderate & $\begin{array}{l}\text { The nonlinear behaviour of arch dam is shown up in the form of contraction opening and cracking; nonpenetrating } \\
\text { cracks appear on the arch dam, and the length of cracks is small; damage may occur downstream face in the centre of } \\
\text { dam, which has a certain influence on the seismic performance of the dam body, but it will reach the normal state of use } \\
\text { in short time after slight repair }\end{array}$ \\
\hline III & Serious & $\begin{array}{l}\text { Penetrating cracks appear in the abutment and centre of the arch dam, and the length of cracks is large; the arch dam is } \\
\text { collapsed, which has a serious impact on the seismic performance of dam body }\end{array}$ \\
\hline
\end{tabular}

TABLE 4: Mean values of damage indices under various limit states.

\begin{tabular}{lcc}
\hline & & Index to limit states \\
Limit states & $D_{g, 1}$ & SJO (m) \\
\hline Limit state 1-minor & 0.0030 & 0.00114 \\
Limit state 2-moderate & 0.0146 & 0.0285 \\
Limit state 3-serious & 0.117 & 0.191 \\
\hline
\end{tabular}

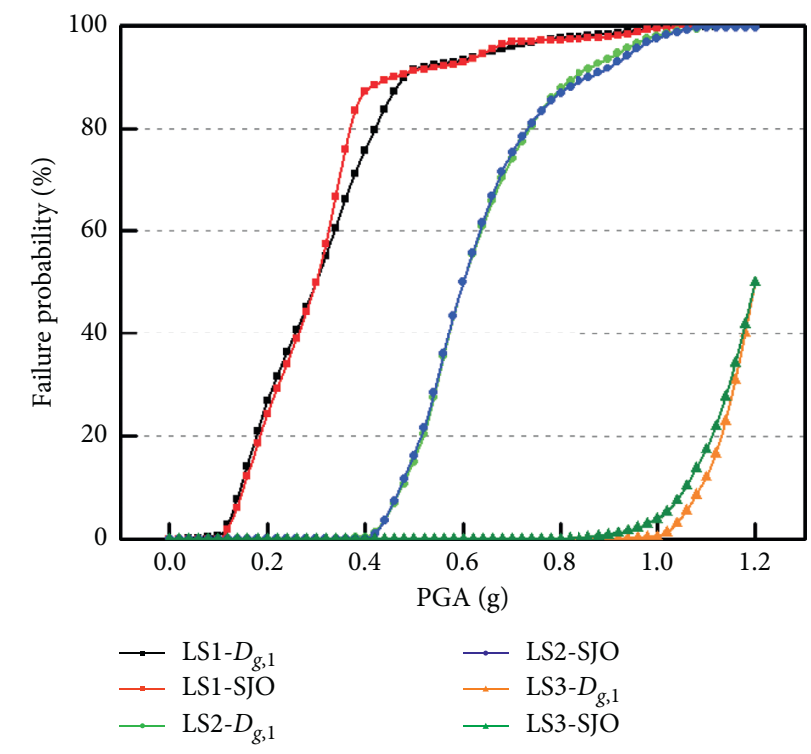

Figure 21: Fragility curves of damage and joint opening indices.

$$
\begin{aligned}
& D_{g, 1}=0.567 \mathrm{SJO}+0.0005 \\
& D_{g, 1}=2.238 \mathrm{MVD}-0.024 \\
& D_{g, 1}=0.479 \mathrm{SJO}+0.576 \mathrm{MVD}-0.01 .
\end{aligned}
$$

\section{Fragility Analysis}

Three limit states are defined by Table 3, and the descriptions of three limit states are given based on response results of nonlinear dynamic analysis. According to the description, the corresponding phenomena and the value of dynamic response threshold are determined for the usage of fragility analysis. Regarding the mean value as an index and dividing the cases into three failure grades according to the intensity of ground motions, limit state 1 -minor $(<0.3 \mathrm{~g})$, limit state 2 moderate (0.3-0.6 g), and limit state 3 -serious (0.6-1.2 g) are defined. The mean damage indices under three limit states are listed in Table 4. In conjunction with the samples of fragility indices and the selection of limit states value, the failure probability of indices is obtained at different intensities by assuming these fragility indices obey a lognormal normal distribution (equation (6)). On the basis of the investigation above, two indicators with a strong correlation are compared. Figure 21 describes the evolution of fragility indices such as damage indices and joint opening indices including $D_{g, 1}$ and SJO. As shown, the probability curves of these fragility indices exhibit remarkable consistency because of the strong correlation between the two indicators.

In conclusion, the dynamic results show that the dam firstly suffers initial damage to its base surface near the 
upstream face under a history with an intensity of $0.3 \mathrm{~g}$ and then suffers damage in the middle of its downstream surface at $0.6 \mathrm{~g}$. Thus, the indices $D_{g, 2}$ and deformation are very sensitive to the initial damage on the base surface near the upstream face of the dam. The fragility indices $D_{g, 1}$, MJO, and SJO are very sensitive to the damage in the middle of the downstream surface, and the fragility indices $D_{g, 2}$ and deformation have some intrinsic relationship as do the fragility indices $D_{g, 1}, \mathrm{MJO}$, and SJO. In the practice of dam monitoring, deformation monitoring is the main method recommended. Thus, these fragility indices SJO and deformation can reveal the failure mode of such an arch dam.

\section{Conclusions}

The analysis of seismic dynamic response and performance for the Baihetan arch dam-reservoir-foundation system is made by determining failure mode, proposing fragility indices, and analysing probability distributions when the dam is subjected to ETAHs for increasing seismic intensity measure. Several conclusions and recommendations are proposed:

(1) Cracking firstly occurs on the base surface near the upstream face and then in the middle of the downstream surface with increasing seismic intensity measure. The damage indices $D_{g, 1}$ and $D_{g, 2}$ follow similar exponential evolutionary trends with increasing seismic intensity measure. The damage indicator $D_{g, 1}$ is more sensitive to seismic intensity than $D_{g, 2}$. The discreteness of these damage indices will rapidly decline at large seismic intensity measure.

(2) The peak joint openings firstly occur at the crest centre and then near the abutment with increasing seismic intensity measure. The joint opening indices MJO and SJO follow similar exponential evolutionary trends with increasing seismic intensity measure. The scatter of the MJO is more significant than that of the SJO, suggesting that SJO is a better joint opening indicator.

(3) The fragility indices $D_{g, 2}$ and deformation are very sensitive to the initial cracking on the base surface near the upstream face of the dam. The fragility indices $D_{g, 1}, \mathrm{MJO}$, and SJO are very sensitive to the cracking in the middle of the downstream surface. In the practice of dam monitoring, joint opening and deformation monitoring are the main indices recommended because these fragility indices can reveal the types of damage to such an arch dam.

(4) The coefficients of variation and correlation are used to analyse each index and show that the damage index $D_{g, 1}$ has a good correlation with the SJO index. Three limit states are proposed according to the damage distribution and yield points seen in ETA response curves. In addition, the linear equivalent relationship between the two indices is established, and the derived fragility curves also confirmed the consistency of the two indices, which is of great help in engineering practice.

(5) On the basis of a multivariate regression analysis, the relationship between damage index Dg, 1 and joint opening SJO index, deformation MVD index, is determined, and the coefficient $R^{2}$ is greater than that of any single index, which provides a foundation for structural damage prediction and seismic performance evaluation; however, the effects of other factors such as earthquake wave duration on the seismic fragility of an arch dam are still not considered. More research is thus required in the future.

\section{Data Availability}

The data used to support the findings of this study are included within the article.

\section{Conflicts of Interest}

The authors declare that they have no conflicts of interest.

\section{Acknowledgments}

This study was supported by the National Key R \& D Programme of China (no. 2017YFC0404900), the Funds of the Innovation Support Plan for Researchers in Dalian (no. 2016RQ015), and the National Natural Science Foundation of China (no. 51779032).

\section{References}

[1] C. A. Goulet, C. B. Haselton, J. Mitrani-Reiser et al., "Evaluation of the seismic performance of a code-conforming reinforced-concrete frame building-from seismic hazard to collapse safety and economic losses," Earthquake Engineering \& Structural Dynamics, vol. 36, no. 13, pp. 1973-1997, 2007.

[2] J. M. Bracci, S. K. Kunnath, and A. M. Reinhorn, "Seismic performance and retrofit evaluation of reinforced concrete structures," Journal of Structural Engineering, vol. 123, no. 1, pp. 3-10, 1997.

[3] B. R. Mace, K. Worden, and G. Manson, "Uncertainty in structural dynamics," Journal of Sound and Vibration, vol. 288, no. 3, pp. 423-429, 2005.

[4] J.-T. Wang, "Investigation of damping in arch dam-waterfoundation rock system of Mauvoisin arch dam," Soil Dynamics and Earthquake Engineering, vol. 31, no. 1, pp. 33-44, 2011.

[5] G. Lin and Z. Hu, "Earthquake safety assessment of concrete arch and gravity dams," Earthquake Engineering and Engineering Vibration, vol. 4, no. 2, pp. 251-264, 2005.

[6] X. Du and J. Tu, "Nonlinear seismic response analysis of arch dam-foundation systems-part II opening and closing contact joints," Bulletin of Earthquake Engineering, vol. 5, no. 1, pp. 121-133, 2007.

[7] Q. Xu, J.-y. Chen, J. Li, and H.-y. Yue, "A study on the contraction joint element and damage constitutive model for concrete arch dams," Journal of Zhejiang University Science A, vol. 15, no. 3, pp. 208-218, 2014. 
[8] Q. Xu, J.-y. Chen, J. Li, and C.-f. Zhao, "Influence of seismic input on response of Baihetan arch dam," Journal of Central South University, vol. 21, no. 6, pp. 2437-2443, 2014.

[9] M. A. Hariri-Ardebili and M. R. Kianoush, "Integrative seismic safety evaluation of a high concrete arch dam," Soil Dynamics and Earthquake Engineering, vol. 67, pp. 85-101, 2014.

[10] M. A. Hariri-Ardebili, S. M. Seyed-Kolbadi, and M. R. Kianoush, "FEM-based parametric analysis of a typical gravity dam considering input excitation mechanism," Soil Dynamics and Earthquake Engineering, vol. 84, pp. 22-43, 2016.

[11] H. Ren, T. C. Li, H. F. Chen, and L. H. Zhao, "Nonlinear simulation of arch dam cracking with mixed finite element method," Water Science and Engineering, vol. 1, no. 2, pp. 88-101, 2008.

[12] J.-T. Wang, A.-Y. Jin, X.-L. Du, and M.-X. Wu, "Scatter of dynamic response and damage of an arch dam subjected to artificial earthquake accelerograms," Soil Dynamics and Earthquake Engineering, vol. 87, pp. 93-100, 2016.

[13] J.-T. Wang, D.-D. Lv, F. Jin, and C.-H. Zhang, "Earthquake damage analysis of arch dams considering dam-water-foundation interaction," Soil Dynamics and Earthquake Engineering, vol. 49, pp. 64-74, 2013.

[14] J. Pan, C. Zhang, J. Wang, and Y. Xu, "Seismic damagecracking analysis of arch dams using different earthquake input mechanisms," Science in China Series E: Technological Sciences, vol. 52, no. 2, pp. 518-529, 2009.

[15] M. Karalar and M. Cavusli, "Effect of normal and shear interaction stiffnesses on three-dimensional viscoplastic creep behaviour of a CFR dam," Advances in Civil Engineering, vol. 2018, Article ID 2491652, 17 pages, 2018.

[16] M. Karalar and M. Cavusli, "Evaluation of 3D nonlinear earthquake behaviour of the Ilisu CFR dam under far-fault ground motions," Advances in Civil Engineering, vol. 2019, Article ID 7358710, 15 pages, 2019.

[17] M. Karalar and M. Cavusli, "Seismic effects of epicenter distance of earthquake on 3D damage performance of CG dams," Earthquakes and Structures, vol. 18, no. 2, pp. 201-213, 2020.

[18] M. Karalar and M. Cavusli, "Assessing 3D seismic damage performance of a CFR dam considering various reservoir heights," Earthquakes and Structures, vol. 16, no. 2, pp. 221234, 2019.

[19] M. Karalar and M. Cavusli, "Examination of 3D long-term viscoplastic behaviour of a CFR dam using special material models," Geomechanics and Engineering, vol. 17, no. 2, pp. 119-131, 2019.

[20] M. E. Kartal, M. Cavusli, and M. Genis, "Investigation of three dimensional nonlinear analysis of atatürk dam considering settlement monitoring," International Journal of Geomechanics, vol. 16, no. 2, 2019.

[21] M. E. Kartal, M. Cavusli, and A. B. Sunbul, "Assessing seismic response of a $2 \mathrm{D}$ roller-compacted concrete dam under variable reservoir lengths," Arabian Journal of Geosciences, vol. 10, no. 22, pp. 1-18, 2017.

[22] B. Demirtas, A. Bayraktar, and A. Dumanoglu, "Model updating effects on the seismic behavior of tall buildings under far and near-fault ground motions," Research on Engineering Structures \& Materials, vol. 3, no. 2, pp. 99-112, 2016.

[23] B. Asgarian and A. Jalaeefar, "Incremental dynamic analysis of steel braced frames designed based on the first, second and third editions of the Iranian seismic code (standard no.
2800)," The Structural Design of Tall and Special Buildings, vol. 20, no. 2, pp. 190-207, 2011.

[24] D. Vamvatsikos and C. A. Cornell, "Incremental dynamic analysis," Earthquake Engineering \& Structural Dynamics, vol. 31, no. 3, pp. 491-514, 2002.

[25] A. K. Chopra and R. K. Goel, "A modal pushover analysis procedure for estimating seismic demands for buildings," Earthquake Engineering \& Structural Dynamics, vol. 31, no. 3, pp. 561-582, 2002.

[26] J. W. Baker, "Efficient analytical fragility function fitting using dynamic structural analysis," Earthquake Spectra, vol. 31, no. 1, pp. 579-599, 2015.

[27] M. Alembagheri and M. Ghaemian, "Incremental dynamic analysis of concrete gravity dams including base and lift joints," Earthquake Engineering and Engineering Vibration, vol. 12, no. 1, pp. 119-134, 2013.

[28] M. Alembagheri and M. Ghaemian, "Damage assessment of a concrete arch dam through nonlinear incremental dynamic analysis," Soil Dynamics and Earthquake Engineering, vol. 44, pp. 127-137, 2013.

[29] J.-T. Wang, M.-X. Zhang, A.-Y. Jin, and C.-H. Zhang, "Seismic fragility of arch dams based on damage analysis," Soil Dynamics and Earthquake Engineering, vol. 109, pp. 58-68, 2018.

[30] R. Pang, B. Xu, X. Kong, and D. Zou, "Seismic fragility for high CFRDs based on deformation and damage index through incremental dynamic analysis," Soil Dynamics and Earthquake Engineering, vol. 104, pp. 432-436, 2018.

[31] H. E. Estekanchi, A. Vafai, and M. Sadeghazar, "Endurance time method for seismic analysis and design of structures," Scientia Iranica, vol. 11, no. 4, pp. 361-370, 2004.

[32] V. Valamanesh, H. E. Estekanchi, and A. Vafai, "Characteristics of second generation endurance time acceleration functions," Scientia Iranica, vol. 17, no. 1, pp. 53-61, 2010.

[33] V. Valamanesh, H. E. Estekanchi, A. Vafai, and M. Ghaemian, "Application of the endurance time method in seismic analysis of concrete gravity dams," Scientia Iranica, vol. 18, no. 3, pp. 326-337, 2011.

[34] M. A. Hariri-Ardebili and H. Mirzabozorg, "Estimation of probable damages in arch dams subjected to strong ground motions using endurance time acceleration functions," KSCE Journal of Civil Engineering, vol. 18, no. 2, pp. 574-586, 2014.

[35] M. A. Hariri-Ardebili, Y. Zarringhalam, H. E. Estekanchi, and M. Yahyai, "Nonlinear seismic assessment of steel moment frames using time-history, incremental dynamic, and endurance time analysis methods," Scientia Iranica, vol. 20, no. 3, pp. 431-444, 2013.

[36] M. A. Hariri-Ardebili, H. Mirzabozorg, and H. E. Estekanchi, "Nonlinear seismic assessment of arch dams and investigation of joint behavior using endurance time analysis method," Arabian Journal for Science and Engineering, vol. 39, no. 5, pp. 3599-3615, 2014.

[37] M. A. Hariri-Ardebili, H. Mirzabozorg, and R. Kianoush, “A study on nonlinear behavior and seismic damage assessment of concrete arch dam-reservior-foundation system using endurance time analysis," Iran University of Science \& Technology, vol. 2, no. 4, pp. 573-606, 2012.

[38] H. T. Riahi and H. E. Estekanchi, "Seismic assessment of steel frames with the endurance time method," Journal of Constructional Steel Research, vol. 66, no. 6, pp. 780-792, 2010.

[39] H. T. Riahi, H. E. Estekanchi, and S. S. Boroujeni, "Application of endurance time method in nonlinear seismic analysis of steel frames," Procedia Engineering, vol. 14, pp. 3237-3244, 2011. 
[40] H. E. Estekanchi, H. T. Riahi, and A. Vafai, "Application of endurance time method in seismic assessment of steel frames," Engineering Structures, vol. 33, no. 9, pp. 2535-2546, 2011.

[41] J. Lee and G. L. Fenves, "A plastic-damage concrete model for earthquake analysis of dams," Earthquake Engineering \& Structural Dynamics, vol. 27, no. 9, pp. 937-956, 1998.

[42] J. Goodman, "Structural fragility and principle of maximum entropy," Structural Safety, vol. 3, no. 1, pp. 37-46, 1985.

[43] M. A. Hariri-Ardebili and V. E. Saouma, "Seismic fragility analysis of concrete dams: a state-of-the-art review," Engineering Structures, vol. 128, pp. 374-399, 2016.

[44] P. B. Tekie and B. R. Ellingwood, "Seismic fragility assessment of concrete gravity dams," Earthquake Engineering \& Structural Dynamics, vol. 32, no. 14, pp. 2221-2240, 2003.

[45] K.-J. Bathe and A. Chaudhary, "A solution method for planar and axisymmetric contact problems," International Journal for Numerical Methods in Engineering, vol. 21, no. 1, pp. 65-88, 1985.

[46] J.-T. Wang, C.-H. Zhang, and F. Jin, "Nonlinear earthquake analysis of high arch dam-water-foundation rock systems," Earthquake Engineering \& Structural Dynamics, vol. 41, no. 7, pp. 1157-1176, 2012.

[47] C. H. Zhang, J. W. Pan, and J. T. Wang, "Influence of seismic input mechanisms and radiation damping on arch dam response," Soil Dynamics and Earthquake Engineering, vol. 29, pp. 1282-1293, 2009.

[48] J. Liu, Y. Du, X. Du, Z. Wang, and J. Wu, “3D viscous-spring artificial boundary in time domain," Earthquake Engineering and Engineering Vibration, vol. 5, no. 1, pp. 93-102, 2006.

[49] Z. P. Liao and J. B. Liu, "Elastic wave motion in discrete grids," Earthquake Engineering and Engineering Vibration, vol. 6, no. 2, pp. 1-16, 1986, (in Chinese).

[50] J. Huang, M. Zhao, and X. Du, "Non-linear seismic responses of tunnels within normal fault ground under obliquely incident $\mathrm{P}$ waves," Tunnelling and Underground Space Technology, vol. 61, pp. 26-39, 2017.

[51] H. Mirzabozorg and M. Ghaemian, "Non-linear behavior of mass concrete in three-dimensional problems using a smeared crack approach," Earthquake Engineering \& Structural Dynamics, vol. 34, no. 3, pp. 247-269, 2005.

[52] H. M. Westergaard, "Water pressures on dams during earthquakes," Transactions of the American Society of Civil Engineers, vol. 98, pp. 418-433, 1933.

[53] J. Pan, Y. Xu, and F. Jin, "Seismic performance assessment of arch dams using incremental nonlinear dynamic analysis," European Journal of Environmental and Civil Engineering, vol. 19, no. 3, pp. 305-326, 2015. 